\title{
Nadir Toprak Minerallerinin Fiziksel Ayrılması ve Flotasyonu: Derleme
}

\author{
Ayşe Erdem*, Yurdaer Babuçcuoğlu, Haydar Güneş, Hüseyin Eren Obuz, Elif Özdemir, Çiğdem Kara, Şölen \\ Diktepe, Mekkiye Betül Akgül, Buse Özen İlik, Hasan Akçay \\ Maden Tetkik ve Arama Genel Müdürlüğ̈̈ Maden Analizleri ve Teknoloji Dairesi, 06530, Ankara, Türkiye \\ *ayse.erdem@mta.gov.tr@, yurdaer.babuccuoglu@mta.gov.tr@, haydargunes35@gmail.com $\mathbb{D}$, \\ h.eren.obuz@gmail.com $\mathbb{D}$, elif.ozdemir@mta.gov.tr@,cgdmtrhl92@gmail.com@, \\ diktepesolen@gmail.com $\mathbb{D}$, mbetul.akgul@gmail.com $\mathbb{D}$, buseozen9@gmail.com $\mathbb{\mathbb { D }}$, \\ hasan.akcay@mta.gov.tr@D \\ Makale gönderme tarihi: 28.04.2021, Makale kabul tarihi: 11.07.2021
}

\begin{abstract}
$\ddot{O} \mathbf{z}$
Nadir toprak elementleri (NTE) skandiyum, itriyum ve lantanit serisinde yer alan 17 adet metalik elementi içermekte ve kimyasal olarak birbirine benzer özellikler göstermektedir. $\mathrm{Bu}$ elementler 250 'den fazla mineralin içerisinde bulunmakta ve bu minerallerden bastnazit, monazit ve ksenotim işletilmektedir. Günümüzde bu elementleri içeren maden yataklarının keşifleri devam etmekte ve yeni yataklar bulunmaktadır. NTE yatakları karbonatlar, alkali/peralkali magmatik kayaçlar, plaser ve iyon adsorpsiyon killer olmak üzere 4 farklı sınıfa ayrılmaktadır. Bu çalışmada, NTE hakkında genel bilgi, kullanım alanları, rezerv durumu ve üretim miktarı ile ilgili veriler verilmiştir. Ayrıca, NTE minerallerinin fiziksel zenginleştirme yöntemlerinden bahsedilmiştir. Bu yöntemlerden ön zenginleştirmede en sık kullanılan flotasyon yöntemi üzerine yapılan çalışmalar, kullanılan reaktifler ve mekanizmaları incelenmiş̧ir.
\end{abstract}

Anahtar Kelimeler: Bastnazit, fiziksel zenginleştirme, flotasyon, monazit, Nadir toprak elementleri

\section{Physical Separation and Flotation of Rare Earth Minerals: Review}

\begin{abstract}
Rare-earth elements (REE) defined as 17 metallic elements includes scandium, yttrium and lanthanide series and have similar chemically properties. REE are found in more than 250 minerals, however only a few them used for productions such as bastnasite, monazite and xenotime. Nowadays, exploration of ore deposits containing REE continues and new deposits are discovered. REE ore deposits can be divided into 4 different groups as carbonates, alkali/peralkaline igneous rocks, placer and ion adsorption clays. In this study, general information about REE, usage areas, reserve situation and production amount are given. Physical separation methods information are also given. Among these methods, studies on the most commonly used flotation method, used reagents and their mechanisms were examined.
\end{abstract}

Keywords: Bastnasite, physical separation, flotation, monazite, rare earth elements

\section{GİRIŞ̧}

Nadir toprak elementleri (NTE) terimi skandiyum, itriyum ve lantanit serisinde yer alan ve kimyasal özellikleri benzer olan toplam 17 adet metalik elementi tanımlamaktadır. $\mathrm{Bu} 17$ elementten sadece $\mathrm{Pm}$ sembolüne sahip prometyum sentetik olarak üretilmiş olup geri kalan 16 element doğada bulunmaktadır. Kimyasal olarak birbirlerine benzer özellikte olduklarından dolayı mineralde ve cevher yataklarında sürekli bir arada bulunmaktadır (Krishnamurthy \& Gupta, 2015). NTE temelde iki alt gruba ayrilmaktadır. Bunlar; hafif nadir toprak elementleri (hNTE) ve ağır nadir toprak elementleridir (aNTE). hNTE seryum grubu olarak bilinmekte ve lantandan başlayarak evropiyuma kadar gitmektedir. aNTE ise itriyum grubu olarak bilinmekte ve gadolinyumdan başlayarak lütesyuma kadar olan elementleri ve ek olarak itriyumu da içermektedir. Skandiyum ve itriyumun NTE içerisinde yer almalarının nedeni, NTE ile benzer çekirdek yapısı özelliklerini göstermeleridir. NTE keşfedilmesi ile birlikte ticari, endüstriyel, tıbbi, uzay uygulamaları gibi birçok alanda kullanılmaya başlanmıştır. NTE'nin elektromanyetik, manyetik ve kimyasal 
özellikleri sayesinde bu alanlarda önemli bir yere sahip olmuştur (Jha, 2014; Obuz vd., 2018).

NTE mineralleri, doğada tek başına bulunmazlar. Genellikle, bir mineralin içerisinde birden fazla NTE birlikte bulunabilmektedir. Bugüne kadar 250'den fazla NTE içeren mineral tespit edilmiştir. Buna rağmen en fazla 10-12 tane NTE içeren mineral değerli olarak görülmektedir. $\mathrm{Bu}$ mineraller sirasiyla; bastnazit, monazit, ksenotim, floserit, parisit, fergusonit, gadolinit, sinçisit, polikraz ve loparittir (Zhang vd., 2016).

$\mathrm{Bu}$ çalışma kapsamında NTE içeren karbonatl1, oksitli, fosfatlı ve silikatlı mineraller incelenmiştir. Çalışma içeriğinde geçen karbonatlı mineraller ansilit $\left(\mathrm{Sr}(\mathrm{Ce}, \mathrm{La})\left(\mathrm{CO}_{3}\right)_{2}(\mathrm{OH}) \cdot \mathrm{H}_{2} \mathrm{O}\right)$, basnazit $\left((\mathrm{Ce}, \mathrm{La})\left(\mathrm{CO}_{3}\right) \mathrm{F}\right), \quad$ parisit $(\mathrm{Ca}$ $\left.(\mathrm{Ce}, \mathrm{La})_{2}\left(\mathrm{CO}_{3}\right)_{3} \mathrm{~F}_{2}\right)$ ve sinçisittir $\quad(\mathrm{Ca}$ $\left.(\mathrm{Ce}, \mathrm{La})\left(\mathrm{CO}_{3}\right)_{2} \mathrm{~F}\right)$. NTE içeren oksitli mineraller sirayısiyla, kolumbit $\left((\mathrm{Fe}, \mathrm{Mn}) \mathrm{Nb}_{2} \mathrm{O}_{6}\right)$, fergusonit $\left(\mathrm{YNbO}_{4}\right)$, loparit $\left((\mathrm{Ce}, \mathrm{Na}, \mathrm{Ca})(\mathrm{Ti}, \mathrm{Nb}) \mathrm{O}_{3}\right)$ ve piroklordur $\left((\mathrm{Na}, \mathrm{Ca})_{2} \mathrm{Nb}_{2} \mathrm{O}_{6}(\mathrm{OH}, \mathrm{F})\right)$. NTE içeren fosfatl mineraller apatit $\left((\mathrm{Ca}, \mathrm{NTE})_{5}\left(\mathrm{PO}_{4}\right)_{3}(\mathrm{~F}, \mathrm{Cl}, \mathrm{OH})\right), \quad$ monazit $\left((\mathrm{Ce}, \mathrm{La}, \mathrm{Nd}, \mathrm{Th}) \mathrm{PO}_{4}\right)$ ve ksenotimdir $\left(\mathrm{YPO}_{4}\right)$. NTE içeren silikat mineralleri allanit $\left((\mathrm{Ca}, \mathrm{Ce}, \mathrm{Y})_{2}\left(\mathrm{Al}, \mathrm{Fe}^{2+}, \mathrm{Fe}^{3+}\right)_{3}\left(\mathrm{SiO}_{4}\right)_{3}(\mathrm{OH})\right)$, gadolinit ( $\left.(\mathrm{Ce}, \mathrm{La}, \mathrm{Nd}, \mathrm{Y})_{2} \mathrm{Fe}^{2+} \mathrm{Be}_{2} \mathrm{Si}_{2} \mathrm{O}_{10}\right)$, steenstupine $\left(\mathrm{Na}_{14} \mathrm{Ce}_{6} \mathrm{Mn}_{2} \mathrm{Fe}_{2}(\mathrm{Zr}, \mathrm{Th})\left(\mathrm{Si}_{6} \mathrm{O}_{18}\right)_{2}\left(\mathrm{PO}_{4}\right)_{7} \cdot 3 \mathrm{H}_{2} \mathrm{O}\right)$, titanit $\left(\mathrm{Ca}(\mathrm{Ti}, \mathrm{NTE}) \mathrm{SiO}_{5}\right)$ ve zirkondur ((Zr,NTE)SiO $\left.{ }_{4}\right)$ (Krishnamurthy \& Gupta, 2015).

NTE'nin ağırlık, yoğunluk, ergime noktası, kaynama noktası gibi fiziksel kimyasal ve termal özellikleri Ek 1'de verilmiştir. Tabloda bahsedilen özelliklerden, NTE'nin birbirleri içerisinde çok benzer olduğunu göstermektedir. Bu benzerliklerin bir sonucu olarak NTE ayrımının zor olduğu söylenebilmektedir.

\section{Kullanım Alanları}

NTE benzersiz manyetik, fosforesan ve katalitik özellikleri sayesinde günümüzde büyük stratejik öneme sahiptir. Yeni nesil motor üreticileri, manyetik ayırıcı, taşımacılık ve elektronik endüstrileri bu elementleri talep etmektedir. Ayrıca, içerisinde bulundukları malzemeyi hafifletmekte ve yüksek sıcaklığa karşı direncini artırmaktadır. Sc-Al, Sc-Mg, Y-Al, Y-Mg ve Nd-Mn gibi nadir toprak alaşımları, yüksek sıcaklıklarda korozyon direncini artırmaları ve kuvvetli oksitlenmeyi önleyici rolleri sayesinde, metalurjide ve birçok alanda yaygın olarak kullanılmaktadır. Örneğin bu elementler cep telefonlar1 ve televizyonlar, LED ampuller ve rüzgar türbinleri teknolojilerinde kritik öneme sahiptir (Balaram, 2019; Güneş vd., 2018)

Son otuz yıl boyunca bilgisayar belleği, DVD'ler, şarj edilebilir piller, oto katalitik konvertörler, süper mıknatıslar, cep telefonları, LED aydınlatma, süper iletkenler, cam katkı maddeleri gibi çeşitli teknoloji cihazlarında, floresan malzemeleri, fosfat bağlama maddeleri, güneş panelleri ve manyetik rezonans görüntüleme (MRI) malzemelerin üretiminde NTE kullanılmaktadır. NTE'nin dolmamış 4f elektronik yapılarından kaynaklanan eşsiz fiziksel, kimyasal, manyetik ve parlaklık özellikleri nedeniyle, birçok teknolojik üretimde avantaj sağlamaktadır. Örneğin, düşük enerji tüketimi, yüksek verimlilik, minyatürleștirme, hız, dayanıklılık ve termal kararlı1ık gibi birçok teknolojik avantaj sağlamaya yardımcı olur. Tüm yüksek teknoloji cihazlarında son derece önemli bileşenler olduklarından, bu elementlere "Modern Endüstrinin Vitaminleri" denilmektedir (Balaram, 2019).

Y1llı yaklaşık 240 bin ton üretim/kullanım miktarına sahip NTE, miknatıs (yeni nesil otomobillerde), katalizör (araç emisyonları ve petrol parçalama), cam temizleme tozu (televizyon ekranları için), cam veri depolama sürücüleri, yeniden şarj edilebilir piller (özelikle hibrit araçlarda kullanılan) ve fotonikler (luminisans, floresans ve 1 ş1k güçlendirici ekipmanlar) gibi kullanım alanlarına sahiptir (Lucas vd., 2014; USGS, 2021).

NTE'nin en yaygın kullanım alanları; kalıcı mıknatıslar, katalizörler, parlatma tozları, tekrar şarj edilebilir bataryalar, metalurji, fosfor, cam katk1 malzemelerinde ve seramiklerdir. Bu alanlarda en fazla NTE kullanımı \%29 ile kalıcı mıknatıs üretimi, \%21 ile katalizörler, \%13 parlatma tozları ve $\% 12$ cam ve seramikler, $\% 8$ metalurji ve $\% 7$ bataryalar olarak belirtilmiştir (Roskill, 2021).

Nadir toprak elementleri, $\mathrm{CO}_{2}$ ve diğer emisyonları azaltmaya yardımcı olan rüzgar türbinleri, elektrikli araba pilleri ve enerji tasarruflu 1ş1klar da dâhil olmak üzere birçok gelişmiş enerji teknolojisinde kullanılır. Nadir toprak elementleri kompakt floresan aydınlatma (CFL'ler), LED aydınlatma ve fiber optik için 
gereklidir. Nadir toprak mıknatıslarını kullanan yeni bir teknoloji olan manyetik soğutma, ev ve ticari kullanım için buzdolaplarının enerji verimliliğini potansiyel olarak artırabilir. Nadir toprak elementleri, yeni enerji teknolojilerimiz için kritik öneme sahiptir. Nadir toprak elementlerinin sektörlere göre ve elementlere göre olan kullanım alanı tablosu Tablo 1'de sunulmaktadır (Maden Tetkik ve Arama Genel Müdürlügü, 2017).

NTE en fazla tüketen iki ülke \%78,22 ile Çin ve $\% 15,00$ ile Avusutralyadır. Diğer ülkelerde tüketim bu iki ülkeye oranla çok düşük kalmaktadır. Bu iki ülkede sonra en çok tüketenler sırasılla Rusya, Brezilya, Tayland, Vietnamdır (Balaram, 2019).

\section{Rezerv Durumu ve Üretim Miktarları}

NTE'nin bilinen rezerv durumları incelendiğinde en yüksek rezerve 44 milyon ton ile Çin, arından 22 milyon ton ile Vietnam, 21 milyon ton ile Brezilya gelmektedir. Çin, Vietnam ve Avusturalya Dünya rezervinin \%56'sına sahiptir. $\mathrm{Bu}$ ülkelerden sonra bilinen en çok rezerve sahip ülkeler sirasiyla Rusya, Hindistan, Avusturalya, Amerika, Grönland, Türkiye, Tanzanya ve Kanada şeklinde devam etmektedir. Türkiye'de ise bilinen NTE rezervi 953 bin tondur. Dünyada bilinen toplam NTE rezervi 116 milyon tondur (USGS, 2021).

Dünyada NTE üretimi veya NTE maden üretimi yapan firmalar, işletme modelleri, üretim kapasiteleri ve çalıştıkları saha hakkındaki bilgiler Tablo 2'de sunulmaktadır.

\section{FİZIKKSEL YÖNTEMLERLE NTE ZENGINLEŞTIRME}

NTE minerallerinin fiziksel yöntemlerle zenginleştirilmesinde birlikte bulunduğu gang minerallerinin yüzey kimyası (flotasyon), özgül ağırlık, manyetik ve elektriksel özelliklerindeki farklılıklar kullanılmaktadır. Literatürde NTE flotasyonu; manyetik ayırma, elektrostatik ayırma ve gravite yardımıyla ayırma yöntemleri ile zenginleştirilmesinden daha fazla yer tutmaktadır.

Nadir toprak minerallerinin ön zenginleştirilmesinde fiziksel yöntemler, ekonomik olduğundan yaygın şekilde kullanılmaktadır.

Plaser yataklardaki NTE'nin kazanımı için kuru ve yaş yöntemler beraber uygulanmaktadır.
İnce tane boyutlarında $(-100 \mu)$ zenginleştirilmesine gereksinim olduğu hallerde, cevherin yerçekimi yöntemiyle zenginleştirmesi zor olduğundan bu boyuttaki mineraller flotasyonla zenginleştirilmektedir.

\section{Manyetik Ayırma}

Manyetik ayırmayla zenginleştirme yönteminde, ilgili mineralin ve gang minerallerinin manyetik duyarlılıklarındaki farklilıklar yardımıyla ayırma yapılır. Mineraller manyetik alan davranışlarına göre üç farklı kategoride gruplandırılabilir; paramanyetik, diyamanyetik ve ferromanyetik. Paramanyetik mineraller manyetik alanların daha yoğun olduğu noktalara çekilirken, diyamanyetik mineraller manyetik alanlardan itilir. Ferromanyetik mineraller, daha düşük manyetik alan şiddetlerinde bile manyetize olurlar (Krishnamurthy \& Gupta, 2015).

Minerallerin manyetik duyarlılık değerlerine bakılarak bu ayrım yapılmaktadır. Diyamanyetik mineraller negatif manyetik duyarlılığa sahipken paramanyetik ve ferromanyetik mineraller pozitif duyarlılığa sahiptir. Ferromanyetik minerallerin manyetik duyarlılığı, paramanyetik minerallere göre oldukça yüksektir (Krishnamurthy \& Gupta, 2015).

Elektron dizilimleri gereği, tamamlanmış $4 \mathrm{f}$ alt kabuğundaki manyetik momentler birbirlerini sönümler, fakat tamamlanmadığ 1 durumlarda farkl1lık manyetik özellikler göstermektedir. NTE ise genellikle, $4 \mathrm{f}$ alt kabuğunda bir miktar manyetik momente sahiptir. $\mathrm{Bu}$ da bir dereceye kadar manyetikleşmiş minerallerin varlığını sağlar. $\mathrm{La}$, $\mathrm{Sc}, \mathrm{Yb}, \mathrm{Lu}$ ve $\mathrm{Y}$ hariç tüm NTE'ler güçlü paramanyetiktir. Dolayısıyla NTE mineralleri, paramanyetik veya diyamanyetik elementlerin varlığına bağlı olarak değişen manyetik özelliklere sahiptir. Düşük sıcaklıklarda paramanyetik özelliklere sahip olan NTE, manyetik alanlara maruz kaldığında ferromanyetik davranış sergilemektedirler (Krishnamurthy \& Gupta, 2015).

NTE'nin manyetik özellikleri Jensen ve Mackintosh (1991) tarafindan çalışılmış ve ağır nadir toprak elementlerinin hafif nadir toprak elementlerinden daha yüksek paramanyetik değerlere sahip olduğu kanıtlanmıştır (Jensen \& Mackintosh, 1991). Örneğin ksenotim, monazitten daha yüksek ağır nadir toprak elementi 
içerdiğinden monazitten daha yüksek manyetik duyarlılığa sahiptir (Ito vd., 1991).

NTE zenginleştirmesinde flotasyon öncesi, ferromanyetik mineralleri (tipik olarak demir içeren gang mineralleri) ayırmak için manyetik ayırma kullanılır. Manyetik ayırma, plaj kumundan monazitin zenginleştirilmesi ve ayrıca monazitin manyetik olmayan gang minerallerinden ayrılmasından önce manyetitin uzaklaştırılmasında çok etkili olabilmektedir (Krishnamurthy \& Gupta, 2015).

\section{Elektrostatik Ayırma}

Bazı mineraller elektrik alanına maruz kaldıklarında iletkenlik özellikleri sergileyebilmektedirler. Elektrostatik ayırmada, mineral partiküllerinin diferansiyel çekiciliğini ve iticiliğini üretmek için elektrik alanının kuvveti kullanılır (Taggart \& Behre, 1945). Ayırma temel olarak bir mineralin uygulanan yüksek voltajda elektrik yükü alma ve tutma yeteneğine bağlidır. Yükün büyüklüğü ve polaritesi, yüklü bölgeler arasındaki mesafe ve ilgili parçacıkların dielektrik sabiti, ayırmaya etki eden faktörlerdir (Pryor, 1965).

Bu teknik, benzer özgül ağırlığa ve manyetik özelliklere sahip gang minerallerinden ksenotim ve monazitin ayrılmasında kullanılmıştır (Zhang \& Edwards, 2012). Rulo tipi elektrostatik separatörle (elektrostatik alan ayarlı) ağırlıkça \%0.6'ya kadar monazit içeren Mısır'da bulunan siyah kum yataklarının davranışı, separatörün farklı değişkenleri kullanılarak incelenmiştir. Çalışmaya göre monazit tanelerinin çoğu tersinir negatif yüke sahiptir ve pozitif yüklü statik elektrota doğru çekilmiştir (Moustafa \& Abdelfattah, 2010).

\section{Gravite Yardımıyla Ayırma}

Gravite yardımıyla ayırma, farklı özgül ağırlıktaki (yoğunluktaki) minerallerin ağır ortam, su veya viskoz bir ortamdaki parçacıklar üzerinde etkili olan kuvvetler yardımıyla birbirlerinden ayrılmasıdır. $\mathrm{Bu}$ kuvvetler; yerçekimi veya merkezkaç kuvveti, kaldırma kuvveti ve sürükleme kuvvetidir. NTE mineralleri nispeten yüksek özgül ağırlıklara (4 ila 7 arasında) sahiptir, bu nedenle gravite yardımıyla ayırmada kuvars gibi düşük özgül ağırlıklı gang minerallerinden rahatlıkla ayrılabilirler. Çin'deki Maoniuping NTE yatağındaki iri taneli bastnazit sallantılı masa vasitasiyla konsantre edilmektedir (Zhang \& Edwards, 2012). Gravite konsantrasyonu ise sahil kumu yataklarının işlenmesinde NTE zenginleştirmesi için yaygin olarak kullanılmaktadır. Başka bir çalışmada da Wifley sallantılı masası, düşük özgül ağırlığa sahip gang minerallerini ayırmak için kullanılmıştır. Gang mineralleri ayrıldıktan sonra paramanyetik monazit konsantresi elde edilmiştir. Ferromanyetik mineralleri atmak için de düşük yoğunluklu manyetik ayırma kullanılmıştır (Moustafa \& Abdelfattah, 2010).

$\mathrm{Bu}$ çalışmalara ek olarak gravite yardımıyla ayırma yöntemi, Bayan Obo bölgesinde bulunan gang minerali olarak silikat içeren bastnazit ve monazit cevherlerine kaba flotasyon ile temizleme flotasyonu arasında kullanılmıştır (Chi vd. 2001; Jardons vd., 2013). Ayrıca santrifüj destekli gravite ayrımı kullanılarak, silikat gang minerallerinden altın gibi özgül ağırlıkta çok büyük farklılıklara sahip mineraller için çok ince parçacıkların bir miktar ayrılması sağlanabilir (Falconer, 2003; Gee vd., 2005).

Çok ince taneli cevherleşmeye sahip olan Türkiye cevherinin gravitik yöntem yardımıyla laboratuvar ölçekli çalışması Özbayoğlu ve Atalay tarafından yapılmıştır. Bu çalışmanın önemli bulgularından bir tanesi, NTE'nin çok ince tane boyutlarında $(<5 \mu \mathrm{m})$ birikmesidir. Aşırı ince öğütmeyi önleyerek ya da ultra ince parçacıkların geri kazanarak bu durumun üstesinden gelinebilmiştir. NTO tenörünün öncelikle aşındırma ile \%28 değerine daha sonra Mozley multi-gravite ayırıc1 kullanılarak yapılan çalışmalarla \%\%35 değerine çıkarılabileceği saptanmıştır (Özbayoğlu \& Atalay, 2000). 
Review article/Derleme makale

DOI: 10.29132 ijpas.922811

Tablo 1. Nadir toprak elementlerinin sektörlere göre kullanım alanları (Maden Tetkik ve Arama Genel Müdürlüğ̈̈, 2017)

\begin{tabular}{|c|c|c|c|c|c|c|c|c|c|c|c|c|c|c|c|c|c|}
\hline Sektörler & Alt Sektörler & $\mathbf{Y}$ & $\mathbf{L a}$ & $\mathrm{Ce}$ & Pr & Nd & $\mathrm{Sm}$ & $\mathbf{E u}$ & Gd & $\mathbf{T b}$ & Dy & Ho & $\mathbf{E r}$ & $\mathbf{T m}$ & $\mathbf{Y b}$ & $\mathbf{L u}$ & Sc \\
\hline Katalizör & Su arıtımı, petrol rafinasyonu & & $\mathbf{X}$ & $\mathbf{X}$ & & & & & & & & & & & & & \\
\hline \multirow{2}{*}{ Seramikler } & Kondansatör & $\mathbf{X}$ & $\bar{X}$ & $\mathbf{X}$ & $\bar{X}$ & $\mathbf{X}$ & $\bar{X}$ & & $\mathbf{X}$ & & $\mathbf{X}$ & & $\mathbf{X}$ & & & & \\
\hline & Sentetik taşlar & $\mathbf{X}$ & & $\mathbf{X}$ & $\mathbf{X}$ & $\mathbf{X}$ & & & & $\mathbf{X}$ & & & $\mathbf{X}$ & & & & \\
\hline \multirow{5}{*}{ Elektronik } & GPS & $\mathbf{X}$ & & & & & & & $\mathbf{X}$ & $\mathbf{X}$ & $\mathbf{X}$ & & & & & & $\bar{X}$ \\
\hline & Havacılık teknolojisi & $\mathbf{X}$ & & $\mathbf{X}$ & $\mathbf{X}$ & $\mathbf{X}$ & & & $\mathbf{X}$ & & & & $\mathbf{X}$ & $\mathbf{X}$ & & & \\
\hline & Hard diskler & & & & $\mathbf{X}$ & $\mathbf{X}$ & & & & & $\mathbf{X}$ & & & & & & \\
\hline & Gece görüş ekipmanı & $\mathbf{X}$ & $\mathbf{X}$ & & & & & & & & & $\mathbf{X}$ & $\mathbf{X}$ & & $\mathbf{X}$ & & \\
\hline & Akıllı telefonlar & $\mathbf{X}$ & $\mathbf{X}$ & $\mathbf{X}$ & $\mathbf{X}$ & $\mathbf{X}$ & $\mathbf{X}$ & & & $\mathbf{X}$ & $\mathbf{X}$ & & & & & & \\
\hline \multirow{3}{*}{ Enerji } & $\begin{array}{l}\text { Yüksek sıcaklık süper } \\
\text { iletkenleri }\end{array}$ & $\mathbf{X}$ & $\mathbf{X}$ & & & $\mathbf{X}$ & $\mathbf{X}$ & $\mathbf{X}$ & $\mathbf{X}$ & & $\mathbf{X}$ & & $\mathbf{X}$ & $\mathbf{X}$ & $\mathbf{X}$ & $\mathbf{X}$ & \\
\hline & Nükleer enerji & $\mathbf{X}$ & & & & & & $\mathbf{X}$ & $\mathbf{X}$ & & $\mathbf{X}$ & & & & & & \\
\hline & Rüzgar türbinleri & & & $\mathbf{X}$ & $\mathbf{X}$ & $\mathbf{X}$ & $\mathbf{X}$ & & & $\mathbf{X}$ & $\mathbf{X}$ & & & & & & \\
\hline \multirow{2}{*}{ Cam } & $\begin{array}{c}\text { Boyama, ağartma, soldurma, } \\
\text { cilalama }\end{array}$ & & & $\mathbf{X}$ & $\mathbf{X}$ & $\mathbf{X}$ & & & & & & & $\mathbf{X}$ & & & & \\
\hline & Ekran & $\mathbf{X}$ & $\mathbf{X}$ & $\mathbf{X}$ & & & & $\mathbf{X}$ & & $\mathbf{X}$ & & & & & & & \\
\hline \multirow{2}{*}{ Manyetizma } & $\begin{array}{c}\text { Manyetik optik } \\
\text { diskler } \\
\end{array}$ & & & & & $\mathbf{X}$ & & & $\mathbf{X}$ & $\mathbf{X}$ & $\mathbf{X}$ & & & & & & \\
\hline & Daimi mıknatıslar & & & $\mathbf{X}$ & $\mathbf{X}$ & $\mathbf{X}$ & $\mathbf{X}$ & & & $\mathbf{X}$ & $\mathbf{X}$ & $\mathbf{X}$ & & & & & \\
\hline İlaç & Tibbi cihazlar ve ilaçlar & $\mathbf{X}$ & $\mathbf{X}$ & & $\mathbf{X}$ & & & $\mathbf{X}$ & $\mathbf{X}$ & & & & & $\mathbf{X}$ & & & \\
\hline Metalurji & Demir çelik, süper alaşımlar & & $\mathbf{X}$ & $\mathbf{X}$ & & & & & & & & & & & & & \\
\hline \multirow{5}{*}{ Optik } & El (elektrolüminesan) & & & $\mathbf{X}$ & $\mathbf{X}$ & & $\mathbf{X}$ & $\mathbf{X}$ & & $\mathbf{X}$ & & & & $\mathbf{X}$ & & & \\
\hline & Floresan lamba & $\mathbf{X}$ & $\mathbf{X}$ & $\mathbf{X}$ & & & & $\mathbf{X}$ & $\mathbf{X}$ & $\mathbf{X}$ & & & & & & & \\
\hline & Metal halit lamba & & & & & $\mathbf{X}$ & & & & & $\mathbf{X}$ & & & $\mathbf{X}$ & & & \\
\hline & Optik lens & $\mathbf{X}$ & $\mathbf{X}$ & & & & & & & & & & & $\mathbf{X}$ & $\mathbf{X}$ & $\mathbf{X}$ & \\
\hline & Katı lazer kaynağ 1 YAG & $\mathbf{X}$ & & & & $\mathbf{X}$ & & & & & & & & & & & \\
\hline
\end{tabular}


Tablo 2. NTE üreten şirketler ve işletme modelleri (Krishnamurthy \& Gupta, 2015)

\begin{tabular}{|c|c|c|c|c|}
\hline İşletme adı & Ülke & İşletme Modeli & $\begin{array}{l}\text { Yıllık üretim } \\
\text { kapasitesi } \\
\text { (ton/yıl) }\end{array}$ & $\begin{array}{c}\text { Ortalama Tenör } \\
\text { (NTO) }\end{array}$ \\
\hline Molycorp Minerals & Kaliforniya, ABD & $\begin{array}{c}\text { Flotasyon/Özütleme/Çöktürme ile } \\
\text { konsantre üretimi }\end{array}$ & 3000 & $\% 8.9$ \\
\hline Lovozersky Mining Company & Kola Yarımadası, Rusya & Flotasyon ile zenginleştirme & $3000-4400$ & $\% 1$ \\
\hline Solikamsk Magnesium Works & Kola Yarımadası, Rusya & $\begin{array}{c}\text { Gravite ve manyetik ayırma ile yan ürün olarak NTE } \\
\text { maden üretimi }\end{array}$ & 6500 & $\% 2-3$ \\
\hline Lynas Corp Mt Weld & Batı Avustralya & Flotasyon ile zenginleştirme & 10500 & $\% 10-12$ \\
\hline Rareco/Great Western Mineral Group & Steenkramskaal, Güney Afrika & $\begin{array}{c}\text { Gravite, manyetik ayırma, flotasyon, kostik } \\
\text { parçalama, asit özütleme, solvent ekstraksiyon, } \\
\text { çöktürme }\end{array}$ & 3000 & $\% 1$ \\
\hline Toyota/Sojitz & Dong Pao, Vietnam & Bilgi Yok & 300 & $\% 5$ \\
\hline $\begin{array}{c}\text { Toyota/Indian Rare } \\
\text { Earths }\end{array}$ & Orissa, Hindistan & $\begin{array}{c}\text { Manyetik ayırma ile monazit } \\
\text { üretimi }\end{array}$ & 5000 & $\% 0.3476$ \\
\hline $\begin{array}{c}\text { Mitsubishi/Neo Material Technologies } \\
\text { Pitinga }\end{array}$ & Brezilya & Manyetik ayırma ile monazit üretimi & 500 & $\% 0.8$ \\
\hline Alkane Resources & Dubbo, Avustralya & $\begin{array}{l}\text { Manyetik ayırma ile monazit } \\
\text { üretimi }\end{array}$ & 2600 & $\% 0.89$ \\
\hline China Minmetals Rare Earth Co & Jiangxi, Çin & Yerinde özütleme, solvent ekstraksiyon,çöktürme & 45000 & $\% 0.5-1$ \\
\hline Inner Mongolia Baotou Steel & Bayan Obo, Çin & $\begin{array}{c}\text { Manyetik ayırma, flotasyon, sallantılı masa, } \\
\text { flotasyon, gravite. } \\
\text { Sülfürik asit kavurması, özütleme, çöktürme, } \mathrm{HCl} \text { ile } \\
\text { özütleme } \\
\begin{array}{c}\text { Solvent ektraksiyon, çöktürme, kalsinasyon Ergimiş } \\
\text { tuz elektrolizi ile metal üretimi }\end{array}\end{array}$ & 55000 & $\% 6.9$ \\
\hline
\end{tabular}




\section{Flotasyon}

Flotasyon, minerallerin yüzey özelliklerinden yaralanılarak mineralleri ayırmak için kullanılan çok amaçlı ve çok yönlü bir yöntemdir. Maden ve proses için ekonomik olmayan olarak sınıflandırılan düşük dereceli ve karmaşı cevherlerin kazanılmasında çok hayati olmuştur (Wills, 2006). Spesifik NTE minerallerinin yüzdürülmesi ile ilgili çeşitli araştırmalar yapılmıştır. Mineralojik farklılıklar NTE minerallerinin yüzdürülmesinde uygulanan parametreleri ve elde edilen sonuçları etkilese bile kullanılan toplayıcıları çoğunluklu hidroksamatlar ve karboksilatlardır (yağ asitleri). Seçimli flotasyon için NTE minerallerinin yüzeyleri, yağ asitleri veya hidroksamat kullanılarak hidrofobik hale getirilirken, mevcut gang mineralleri yüzey hidrofilikliğini artırmak için bastırıcılar ile kaplanır (Jordens vd., 2013).

\section{NTE FLOTASYONU}

Nadir toprak mineralleri genel olarak beraber bulundukları gang mineralleri ile benzer fiziksel ve kimyasal özellikler gösterirler. Bu nedenden ötürü, yüksek selektifli flotasyon reaktifleri gereklidir (Bulatovic, 2010; Ren vd., 2003). Nadir toprak mineralleri flotasyonu, özellikle basnazit ve monazit, tipik olarak hidroksamatlar, karboksilatlar ve fosforik asit esterleri gibi oksihidril toplayıc1larla yapılır (Bulatovic, 2010; Jordens vd., 2013; Ren vd., 2003). $\mathrm{Bu}$ sınıftaki toplayıcılar; fonksiyonel grupları oksijen anyonu ve bir metal katyonunun bağlanacağı bir çift bağlı oksijenden oluşur, oksihidril toplayıcılar olarak anılırlar ki bu üç toplayıcı arasındaki esas farklılık oksijen atomlarının bağlı olduğu atomdur (Bulatovic, 2007a). Bu toplayıcılar, cevherin minerolojisine bağlı olarak birçok değişik bastırıcı ve aktifleştiri ile beraber kullanılabilir.

\section{Bastnazit Flotasyonu \\ Hidroksamatlar ile bastnazit flotasyonu}

Bastnazitin birçok hidroksamat toplayıcılar ile yüzdürülmesi denemeleri, literatürde hem tek mineral hem de cevher kullanıldığı durumlarda başarılı sonuçlar vermiş̧tir. Diğer karbonatlı mineraller olan parisit ve ansilit ile yapılan çalışmalar sınırlıdır. Ancak test edilen hidroksamatlar için bastnazite benzer şekilde iyi sonuç verdiği gözlemlenmiştir (Cui \& Anderson, 2017b, 2017a; Deng \& Hill, 2014; Jordens vd., 2016; Owens vd., 2018) Parisit ve senkisit, bastnazite benzer bir florokarbonat yapısına sahiptir dolayısıyla uygulanacak toplayıcılara benzer şekilde tepki vermeleri olağandır. Ayrıca bu durum bastnazit ve parisit için kullanılan ticari hidroksamat toplayıcılar için aynı zeta potansiyeli değerini verdiğini ispatlayan Owens ve diğ. tarafindan sunulmuştur (Owens vd., 2018). Tek mineral deneyleri dışında, Nechalocho maden yatağından kullanılan bir konsantre içindeki bastnazit ve sinçisit, BHA (benzohidroksamik asit) toplayıcısı ile yüzdürülmek istendiğinde benzer bir davranış1 göstermiştir (Jordens vd., 2016).

Geleneksel bastnazit flotasyonunda, yağlı asitler (karboksilatlar) olarak adlandirılan toplayıcılar kullanılmıştır. Fakat bu flotasyon işleminlerinde seçiciliğin düşük olmasının bir sonucu olarak yükssek miktarda bastırıcı kullanılmadan ve sicaklık artırılmadan kayda değer bir ayrım sağlanamamıştır (Bulatovic, 2007a; Pradip \& Fuerstenau, 1991). Hiroksamat toplayıcılar ise daha yüksek seçiciliğe sahip olduklarından böyle bir dezavantaja sahip değillerdir ve alternatif olarak kullanılabilirlikleri kanıtlanmıştır (Herrera-Urbina vd., 2013).

\section{Karboksilatlar ile bastnazit flotasyonu}

Karboksilatların endüstride en sik olarak kullanılanları; oleik asit, sodyum oleat ve tall yağı olarak adlandırılan oleik, linoleik, palmitik ve stearik asit karışımlarıdır (Bulatovic, 2007a). Daha önce de belirtildiği üzere hidroksamatlardan farklı olarak bastnazit flotasyonunda düşük seçiciliğe sahiptirler. Yine de Bayan Obo cevher yatağında ön flotasyon işlemlerinde kullanılmıştır (Bulatovic, 2010; Houot vd., 1991; Jordens vd., 2013; Zhang \& Edwards, 2012).

Bastnazit yüzeyine sodyum oleat adsorpsiyonu literatürde sıklıkla çalışılmış bir konudur. Maksimum adsorpsiyon ve yüzdürülebilirlik $\mathrm{pH} 9$ değerinde elde edilmiş ve kinetik açıdan kemisorpsiyon mekanizması ile adsorpsiyonun gerçekleştirildiği saptanmıştır (Jordens vd., 2014b; Pavez vd., 1996). Daha yeni çalışmalar da ise pH 4 ve 8 arasında en yüksek adsorpsiyonun gerçekleştiği ve artan $\mathrm{pH}$ ile adsorpsiyonun düştüğü gözlemlenmiştir (Espiritu vd., 2018). $\mathrm{Bu}$ farklılığın sebebi, çalışmalarda bahsedilmemesine rağmen, bastnazit örneklerindeki farklılıklar ve küçük safsılıklardan kaynaklanabilmektedir.

Karboksilatlarda da mineral yüzeyindeki hidroksitlenmiş NTE'lerin flotasyona konu olan esas partiküller olduğu ifade edilmiştir (Pavez vd., 1996). 
Ayrıca Mountain Pass yatağındaki örneklerle yapılan çalışmalarda da sıcaklık artışının ve bastırıcı kullanımının gerekli olduğu belirlenmiştir. Sıcaklık artışının etki etmesinin sebebi, toplayıcının çözünürlügünün artması ile açıklanmaktadır. Çözünürlüğü artan toplayıcı, bastnazit yüzeyindeki NTE ile gang minerallere göre daha fazla etkileşime girebilmektedir. $\mathrm{Bu}$ aşamada kinetik faktörler devreye girmektedir. Bastnazit adsorpsiyonu, kemisorpsiyon mekanizması ile gerçekleştiğinden sıcaklık ile artış gösterirken gang mineraller olan kalsit ve floritin adsorpsiyonu, fiziksel adsorpsiyon davranışları sebebiyle sıcaklıkla ters orantılı olarak ilerlemektedir. Mountain Pass yatağında yapılan çalışmalarda, $75{ }^{\circ} \mathrm{C}$ kritik sıcaklığının üstüne çıkıldığında ters etkiler görülmüş ve gang minerallerin adsorpsiyonu tespit edilmiştir (Jordens vd., 2013).

Çin'deki Weishan yatağında oleik asit tipi bir toplayıc1 ile \%60 üzerinde bir NTE konsantresi elde edilmekte olup, bu proses hakkında literatürde detaylı bir tanımlama bulunmamaktadır (Chi vd., 2001).

\section{Diğer toplayıcılar ile bastnazit flotasyonu}

Diğer toplayıcılar içerisinde en çok çalışılmış olanlar fosforik asit türevi toplayıcılar olsa da bu toplayıcılar bastnazit için hidroksamatlar kadar seçici bir etki göstermemektedir (Espiritu vd., 2018).

Bastnazit için alkil sülfat, sülfonat ve amin toplayıcılar ile seçici bir flotasyon davranışı gözlenmemiş̧ir.

Bastnazit flotasyonunda kullanılan toplayıcılar Tablo 3'te sunulmuştur.

\section{Bastnazit flotasyonunda kullanılan bastırıcılar}

Literatürde, bastnazit flotasyonu çalışmalarında bastrıcı olarak sodyum silikat, lignün sülfonat, sodyum florür ve silika jel kullanılmıştır. Sodyum silikat, gang minerallerini daha iyi yanttlar veriyor olmasına rağmen, bazı durumlarda bastnazit minerali için de bastırıcı olarak kullanılmıştır (Jordens vd., 2013). Lignin sülfonatın, bastnazit ile birlikte barit ve kalsit için de uygun bir bastırıcı olduğu görülmüştür. Ancak barit için daha yüksek bir afinite sağlamıştır. Fazla dozda lignin sülfonat kullanımı ise bastnazit flotasyonu için ters etki yaratmaktadır (Pradip \& Fuerstenau, 1991). Bastırıcı olarak sodyum florür kullanılmas1, sülfür içermeyen mineraller tercih edilmektedir. Yapılan çalışmalarda sodyum florür, silikat ve oksit minerallerinde bastırıcılık gösterememiş ancak diğer bastırıcılar ile birlikte kullanıldığında bastırmayı iyileştirdiği gösterilmiştir (Bulatovic, 2007c). NTE flotasyonunda Silika jel gang mineralleri olan barit, florit ve kalsiti bastırmak için kullanılmıştır (Che vd., 2003). Bastnazit flotasyonunda kullanılan bastırıcılar Tablo 4'te sunulmuştur.

\section{Bastnazit flotasyonunda kullanılan yüzey düzenleyiciler}

Bastnazit flotasyonunda sodyum karbonat, çözeltideki karbonat iyonu miktarının sürekliliğini sağlamak için yaygın olarak kullanılır (Houot vd., 1991; Jordens vd., 2013; Pradip \& Fuerstenau, 1991). Karbonat iyonları hem çözelti pH'ını hem de bastnazit, kalsit ve barit gibi gang minerallerinin yüzey özelliklerini etkiler. Aşırı sodyum karbonat ilavesi bastnazit flotasyonunu bastıracaktır (Pradip \& Fuerstenau, 1991).

\section{Monazit ve Ksenotim Flotasyonu \\ Hidroksamatlar ile monazit ve ksenotim flotasyonu}

NTE'nin flotasyonunda en çok çalışılan ikincil mineral fosfat mineralleridir. Bugüne kadar hidroksamatlar kullanılarak yapılan tek mineral flotasyon çalışmalarında NTE içeren fosfatlı minerallerden sadece monazit ve ksenotim kullanılmıştır.

Cevherden flotasyon çalışmalarında monazit cevherinin temel NTE minerali olduğu çalışmaların sayıs1 azdır. Monazit cevheri, NTE yataklarında genellikle ikincil mineral olarak bulunmaktadır. Ancak flotasyon çalışmalarında, NTE içeren minerallerin ayrı ayrı davranışları yerine toplam NTE miktarı üzerinden incelemeler yapılmıştır. Hidroksamat tipi toplayıcılar ile monazit mineralinin yüzdürebildiği bilinmektedir fakat Nechalocho maden yatağında BHA (benzohidroksamik asit) kullanılarak flotasyon yapıldığında monazit mineralinin, bastnazit ve senkisit minerallerine göre daha düşük kazanım oranına sahip olduğu saptanmıştır (Jordens vd., 2016). Bu benzer durum, Bayan Obo cevherinin naftik hidroksamik asit toplayıcısı ile yüzdürülürken de görülmüştür (Li vd., 2018). Assis ve diğ. bu durumun açıklaması olarak minerallerin çözünebilirliği arasındaki farkın etkisi olduğu teorisini savunmuşlardır (Assis vd., 1996). Bu etkiyi kanıtlar nitelikte bir çalışma olmasa da çözünürlügüu monazitten daha fazla olan ksenotim 
Tablo 3. Bastnazit için literatürde kullanılan toplayıcılar

\begin{tabular}{|c|c|c|c|c|c|}
\hline Toplayıcı Türü & Toplayıcı & Gang Mineral & Diğer Kullanılanlar & pH & Referans \\
\hline \multirow{5}{*}{$\begin{array}{l}\text { Hidroksamik } \\
\text { asitler }\end{array}$} & Hidroksamatlar & $\begin{array}{l}\text { Barit, Kalsit, } \\
\text { Kuvars, Dolomit, }\end{array}$ & $\begin{array}{l}\text { Sodyum Karbonat, Lignin } \\
\text { sülfonat }\end{array}$ & $\begin{array}{l}8-9 \\
9\end{array}$ & $\begin{array}{l}\text { (Pavez vd., 1996; } \\
\text { Pradip } \\
\text { Fuerstenau, 1991) }\end{array}$ \\
\hline & C5-C9 alkil & Barit, Florit, Kalsit & $\begin{array}{l}\text { Sodyum karbonat, sodyum } \\
\text { silikat, sodyum florosilikat }\end{array}$ & 9.3 & (Luo \& Chen, 1984) \\
\hline & Aero 6493 & $\begin{array}{l}\text { Kalsit, Dolomit, } \\
\text { Kuvars }\end{array}$ & & $\begin{array}{l}7-9 \\
9\end{array}$ & $\begin{array}{l}\text { (Azizi vd., 2016; } \\
\text { Sarvaramini } \\
\text { 2016) }\end{array}$ \\
\hline & H205 & Barit, Kalsit & & $8-10$ & (Yang vd., 2017) \\
\hline & Florrea 7510 & Dolomit, Kalsit & Sodyum silikat, Guar gum & $8-9$ & $\begin{array}{l}\text { (Boulanger vd., } \\
\text { 2019) }\end{array}$ \\
\hline \multirow{4}{*}{ Karboksilat } & Sodyum oleat & Dolomit, Kuvars & & $\begin{array}{l}4-8 \\
9\end{array}$ & $\begin{array}{l}\text { (Espiritu vd., 2018; } \\
\text { Jordens vd., 2014b; } \\
\text { Pavez vd., 1996) }\end{array}$ \\
\hline & Benzoik asit & & Potasyum alüm & $4-5$ & (Ren vd., 2000) \\
\hline & Oleik asit & \multirow{2}{*}{$\begin{array}{l}\text { Kalsit, } \\
\text { Selestit }\end{array}$} & \multirow{2}{*}{$\begin{array}{l}\text { Lignin sülfonat, Sodyum } \\
\text { karbonat, sodyum silikat }\end{array}$} & \multirow{2}{*}{10} & \multirow{2}{*}{$\begin{array}{l}\text { (Morrice \& Wong, } \\
\text { 1982) }\end{array}$} \\
\hline & Linoleik asit & & & & \\
\hline \multirow{2}{*}{ Fosforik asitler } & Flotinor 1682 & Dolomit & & $4-8$ & (Espiritu vd., 2018) \\
\hline & SM15 & Kuvars & & $5-9$ & (Jordens vd., 2014b) \\
\hline
\end{tabular}

Tablo 4. Bastnazit flotasyonunda kullanılan bastırıcılar

\begin{tabular}{|c|c|c|c|}
\hline Nadir Toprak Minerali & Bastıricılar & Gang & Kaynak \\
\hline & Sodyum Silikat & $\begin{array}{l}\text { Silikat gang, tuz mineralleri } \\
\text { (florit, barit, kalsit ve } \\
\text { dolomit), demir mineralleri, } \\
\text { zirkon, rutil, şörl ve staurolit }\end{array}$ & (Jordens vd., 2013) \\
\hline \multirow[t]{3}{*}{ Bastnasit } & Lignin Sülfonat & Barit & $\begin{array}{c}\text { (Pradip \& Fuerstenau, } \\
1991)\end{array}$ \\
\hline & Sodyum Florür & Sülfür içermeyen mineraller & (Bulatovic, 2007c) \\
\hline & Silika Jel & Barit, florit, kalsit & (Che vd., 2003) \\
\hline
\end{tabular}


mineralinin OHA (oktilhidroksamik asit) ile adsorpsiyon serbest enerjisi incelendiğinde bastnazit benzeri bir davranış sergilediği gözlemlenmiştir (Zhang \& Honaker, 2017).

\section{Karboksilatlar ile monazit ve ksenotim flotasyonu}

Monazit ve ksenotim flotasyonu için karboksilat tipi toplayıcıların kullanımı, özellikle ağır mineral kumu içeren yataklardan kazanımı da literatürde sıklıkla çalışılmış bir konudur. Bastnazit ile karşılaştırıldığında, sodyum oleatın ve oleik asidin her iki mineralin yüzeyine adsorpsiyonunun, daha geniş $\mathrm{pH}$ aralığında gerçekleştiği gözlemlenmiştir. Maksimum monazit geri kazanımları genellikle pH 69 aralığında meydana geldiği raporlanmıştır (AbakaWood vd., 2017; Abeidu, 1972; Cheng vd., 1993; Espiritu vd., 2018; Pavez vd., 1996; Pavez \& Peres, 1993b). Yapılan adsorpsiyon çalışmalarında $\mathrm{pH}$ aralığ1 için benzer eğilimler gözlenirken, flotasyon tepkisinde farklılıklar olduğu belirtilmektedir. Abeidu tarafindan yapılan çalışmada 4-10 pH aralığını test etmiş ve pH 5 ile 9 arasında yüksek monazit kazanım değerleri elde ederken, maksimum kazanımı pH 7'de elde edilmiştir (Abeidu, 1972). Cheng ve diğ. tarafından yapılan çalışmada ise $\mathrm{pH} 3$ 10 aralığında yüksek kazanım elde edilmiştir (Cheng vd., 1993). Monazit ile yapılan bir başka çalışmada 2$10 \mathrm{pH}$ aralığında yüzdürme işlemi gerçekleştirilmiş olup pH 3 ve 7'de maksimum kazanım gözlemlenmiştir (Pavez vd., 1996; Pavez \& Peres, 1993b). Abaka-wood ve diğ. tarafindan yapılan çalışmada maksimum kazanım pH 9'da gözlemlenirken, pH 5 - 9 aralığında göreceli yüksek bir kazanım görüşmüştür. Ancak yapılan çalışmada $\mathrm{pH} 3$ ve $\mathrm{pH}$ 11'de sert düşüşler olduğu gözlemlenmiştir (Abaka-Wood vd., 2017). Espiritu ve diğ. tarafindan yapılan çalışmada 6-7 pH aralığında maksimum kazanım sağlanırken pH 4 ile pH 8-11 arasında NTE kazanımlarının düştüğü saptanmıştır (Espiritu vd., 2018). Yapılan çalışmalar arasındaki bu farkl1lik, sodyum oleat ve oleik asit kullanılması durumunda, farklı monazit örneklerinin farklı tepki verdiklerini işaret etmektedir. Maksimum ksenotim kazanımı ise genellikle 7-9 pH aralığında meydana gelmektedir (Cheng vd., 1993, 1994; Zhang vd., 2013).

Monazit ve/veya ksenotim içeren NTE yataklarına, karboksilatlar ile flotasyon yapılması, bastnazite göre daha iyi sonuçlar vermiştir. $\mathrm{Bu}$ da bu mineraller arasındaki mineralojik farkl11ıklardan kaynaklanmaktadır. Bazı çalışmalarda, monazit ve ksenotim minerallerinin ağır mineral kumu içeren yataklardan çeşitli bastırıcılar kullanılarak yüksek oranda ve yüksek tenörlerde kazanılabileceğini kanıtlanmıştır (Andrews vd., 1990; Pavez \& Peres, 1994).

Ağır mineral kumu içeren yataklarda karboksilat toplayıcılar etkili olsa da, daha karmaşık yapılara sahip monazit ve/veya ksenotim içeren yataklarda genellikle etkisi görülmemiştir (Filippov vd., 2016; Goode, 2014; Jeong \& Cho, 2014; Satur vd., 2016). Şimdiye kadar bunun tek istisnas1, karboksilat toplayıcılar kullanılarak iki farklı flotasyon akış şemasının önerildiği Avustralya'daki Mount Weld yatağıdır (Chan, 1992; Guy vd., 2000). Mount Weld yatağı şu anda faaliyette olmasına rağmen, flotasyon işlemlerinin detaylarını bildiren bir literatür yoktur.

\section{Diğer toplayıcılar ile monazit ve ksenotim flotasyonu}

Andrews ve diğ., ağır mineral kumları içeren yataklardan monazit ve ksenotim geri kazanımı için dört farklı fosforik asit türevi denemiş ve karboksilatlara göre daha üstün bir kazanım sağladıklarını saptamışlardır. Ayrıca fosforik asit toplayıc1lar ile monazit ve ksenotim flotasyonunun, karboksilatlara göre daha düşük baziklikteki $\mathrm{pH}$ değerlerinde yapılabildiği saptanmıştır (Andrews vd., 1990).

Monazit flotasyonunda alkil sülfatların toplayıcı olarak kullanılabilirliği literatürde kanıtlanmıştır (Abaka-Wood vd., 2017; Abeidu, 1972; Choi \& Whang, 1963; Ferron vd., 1991). Çalışmaların bazıları izoelektrik noktanın altındaki $\mathrm{pH}$ değerlerinde monazitin iyi yüzdürülebilirliğe sahip olduğunu gösterirken (Abeidu, 1972; Choi \& Whang, 1963) bazıları daha geniş bir pH aralığını işaret etmişlerdir (Abaka-Wood vd., 2017). Ayrica sülfonatların da asidik pH aralıklarında monazit için toplayıcı görevi gördüğü araştırmalarla kanıtlanmıştır (McEwen vd., 1976).

Aminlerin monazit için kullanımı da literatürde çalışılmış konulardan biridir. $\mathrm{Bu}$ çalışmalarda dodesilamonyum klorür ve dodesilamin ile monazit kazanımı yapıldığı kanıtlanmıştır (Abeidu, 1972; Choi \& Whang, 1963).

Literatürde monazit ve ksenotim için kullanılan toplayıcılar Tablo 5'te sunumuştur. 
Review article/Derleme makale

DOI: 10.29132/ijpas.922811

Tablo 5. Monazit ve ksenotim için literatürde kullanılan toplayıcılar

\begin{tabular}{|c|c|c|c|c|c|c|}
\hline Mineral & Toplayıcı Türü & Toplayıcı & Gang Mineral & Diğer Kimyasallar & pH & Referans \\
\hline \multirow{6}{*}{ Monazit } & \multirow{6}{*}{$\begin{array}{l}\text { Hidroksamik } \\
\text { asitler }\end{array}$} & Hidroksamatlar & $\begin{array}{l}\text { Zirkon, Rutil, } \\
\text { Kalsit, Dolomit }\end{array}$ & $\begin{array}{l}\text { Sodyum metasilikat, sodyum } \\
\text { metafosfat, Sitrik asit, EDTA }\end{array}$ & 9,10 & $\begin{array}{l}\text { (Pavez vd., 1996; Pavez \& } \\
\text { Peres, 1993a, Zhang \& } \\
\text { Honaker, 2017, 2018) }\end{array}$ \\
\hline & & C5-C9 alkil & Barit, Florit, Kalsit & $\begin{array}{l}\text { Sodyum karbonat, sodyum } \\
\text { silikat, sodyum florosilikat }\end{array}$ & 9.3 & (Luo \& Chen, 1984) \\
\hline & & Aero 6493 & & & $7-9$ & (Sarvaramini vd., 2016) \\
\hline & & Flotinor V3759 & Zirkon, Rutil & Sodyum metasilikat & $9-10$ & (Pavez \& Peres, 1993a) \\
\hline & & Aerofloat 6494 & Kuvars, Hematit & & $7-9$ & (Abaka-Wood vd., 2017) \\
\hline & & AC-3 & $\begin{array}{l}\text { Kaolinit, feldspat, } \\
\text { turmalin, kuvars }\end{array}$ & Sodyum poliakrilat & 10 & (Filippov vd., 2016) \\
\hline \multirow{10}{*}{ Monazit } & \multirow{6}{*}{ Karboksilat } & \multirow{4}{*}{ Sodyum oleat } & Kuvars, Hematit & & 9 & (Abaka-Wood vd., 2017) \\
\hline & & & Dolomit & & $6-7,7$ & $\begin{array}{l}\text { (Espiritu vd., 2018; Espiritu \& } \\
\text { Waters, 2018) }\end{array}$ \\
\hline & & & Zirkon, Rutil & $\begin{array}{l}\text { Sodyum metasilikat, sodyum } \\
\text { sülfür }\end{array}$ & $\begin{array}{l}3,7, \\
6-9\end{array}$ & (Pavez \& Peres, 1993a, 1993b) \\
\hline & & & Zirkon, Piroklor & Sodyum sülfür & 7 & (Zakharov vd., 1967) \\
\hline & & Oleik Asit & Zirkon & Sodyum sülfür & $6-9$ & (Abeidu, 1972) \\
\hline & & \multicolumn{2}{|l|}{ Linoleik asit } & & $4-9$ & (Hyung \& Ki, 1963) \\
\hline & Fosforik asitler & Flotinor 1682 & Dolomit & & $\begin{array}{l}4-8 \\
4-7\end{array}$ & $\begin{array}{l}\text { (Espiritu vd., 2018; Espiritu \& } \\
\text { Waters, 2018) }\end{array}$ \\
\hline & \multirow{3}{*}{ Diğer } & $\begin{array}{l}\text { Sodyum dodesil } \\
\text { sülfat }\end{array}$ & $\begin{array}{l}\text { Zirkon, Kuvars, } \\
\text { Hematit }\end{array}$ & & $\begin{array}{l}1.5- \\
4.5\end{array}$ & $\begin{array}{l}\text { (Abeidu, 1972, Abaka-Wood } \\
\text { vd. 2017) }\end{array}$ \\
\hline & & Armac T & Rutil, İlmenit & & 2.5 & (McEwen vd., 1976) \\
\hline & & Dodesilamin & Zircon & & $8-10$ & (Abeidu, 1972) \\
\hline
\end{tabular}


Review article/Derleme makale DOI: 10.29132/ijpas.922811

Tablo 5 (devamı). Monazit ve ksenotim için literatürde kullanılan toplayıcılar

\begin{tabular}{|c|c|c|c|c|c|c|}
\hline Mineral & Toplayıcı Türü & Toplayıcı & Gang Mineral & Diğer Kullanılanlar & $\mathbf{p H}$ & Referans \\
\hline \multirow{5}{*}{ Ksenotim } & \multirow{3}{*}{ Hidroksamik asitler } & Flotinor V3759 & Zirkon & $\begin{array}{l}\text { Lignin sülfonat, Misır nişastası, } \\
\text { Sodyum metasilikat, Amilopektin, } \\
\text { Quebracho ağacı özü }\end{array}$ & 10 & $\begin{array}{l}\text { (Pereira \& Peres, } \\
1997)\end{array}$ \\
\hline & & \multirow{2}{*}{ OHA } & \multirow[t]{2}{*}{$\begin{array}{l}\text { İlmenit, Zirkon, } \\
\text { Turmalin, Stavrolit }\end{array}$} & Sodyum silikat & 9 & $\begin{array}{l}\text { (Zhang \& } \\
\text { Anderson, 2017b) }\end{array}$ \\
\hline & & & & Lignin sülfonat & $5-9$ & $\begin{array}{l}\text { (Zhang \& } \\
\text { Anderson, 2017a) }\end{array}$ \\
\hline & \multirow{2}{*}{ Karboksilat } & \multirow{2}{*}{ Sodyum oleat } & & & $7,7-8$ & $\begin{array}{l}\text { (Cheng vd., 1993, } \\
\text { 1994) }\end{array}$ \\
\hline & & & $\begin{array}{l}\text { İlmenit, Zirkon, } \\
\text { Turmalin, Stavrolit }\end{array}$ & Sodyum silikat, lignin sülfonat & $7-9$ & $\begin{array}{l}\text { (Zhang \& } \\
\text { Anderson, 2017a) }\end{array}$ \\
\hline
\end{tabular}




\section{Monazit flotasyonunda kullanılan bastırıcılar}

Literatürde, monazit ve ksenotim flotasyonu çalışmalarında bastrıcı olarak sodyum silikat, sodyum florosilikat, sodyum sülfür, sodyum heksametafosfat, silika jel, nişastalar, amilopetkin ve quebracho kullanılmıştır. Sodyum silikatın bastırıcı olarak kullanıldığ 1 durumlarda monazit de bastnazite benzer bir davranış göstermektedir. Gang mineraller daha iyi bastırılsa da, monazit için de bir miktar bastırıcılık etkisi göstermektedir (Jordens vd., 2013). Sodyum florosilikat barit, kalsit ve florit minerallari için bastırıcı olarak kullanılmıştır. Ancak $\mathrm{H}_{205}$ gibi toplayıcılar ile kullanılmamaktadır (Li vd., 1988). Sodyum sülfür kullanılan dozaja göre bastırıcı ya da canlandırıc1 görevi görebilmektedir. Yapılan çalışmalarda düşük dozajlarda monazit, zirkon ve piroklor için canlandırıcı, yüksek dozajlarda ise piroklor ve zirkonlar için bastırıcı görevi görmüştür (Pol'kin vd., 1967; Zakharov vd., 1967). Sodyum heksametafosfat bastırıcisı ise monazitin kalsitten ayrılmasında kullanılmıştır (Zhang \& Honaker, 2018). Silika jel, bastnazitte olduğu gibi monazitte de barit, florit ve kalsit bastırmak için kullanılmıştır (Che vd., 2003). Nişastalar ksenotim ve monazit flotasyonunda rutil, ilmenit ve zirkon için bastırıcı olarak kullanılmıştır (Bulatovic, 2007c; Pereira \& Peres, 1997). Ksenotim ile birlikte bulunan zirkonun bastırılmasında amilopetkin kullanılmıştır. Ancak amilopetkinin, ksenotim için de düşük bir bastırıcı etkiye sahip olduğu görülmüştür (Pereira \& Peres, 1997). Quebracho bastıricisı ile de amilopetkin benzeri bir davranış gözlemlenmiştir (Bulatovic, 2007b). Tablo 6'da kullanılan monazit ve ksenotim için kullanılan bastırıcılar sunulmuştur.

\section{Monazit flotasyonunda kullanılan modifiye ediciler}

Monazit flotasyonunda sitrik asidin yardıme1 olduğu çalışmalarda gözlemlenmiştir (Zhang \& Honaker, 2018). Sitrik asidin, kalsiyum iyonlarına kenetlenerek monazit yüzeyi için bir temizleme etkisi sağladığı önerilmiştir.

EDTA, monazit yüzeyinden kalsiyum iyonlarını temizlemek için kullanılmıştır (Zhang \& Honaker, 2018). EDTA, optimal dozda daha fazla monazit geri dönüşümünü sağlayarak ve yüksek dozajlarda monazit üzerinde daha düşük baskılayıcı etkiye sahip olarak sitrik asit üzerindeki iyileşmeleri sunmuştur (Zhang \& Honaker, 2018).
Filippov vd., kaolin mikalı atıklarından monazitin geri kazanımı için dağıtıcı sodyum poliakrilatın kullanımı üzerine çalışmıştır. Dispersiyon olmadan yüzdürme ile karşılaştırıldığında önemli gelişmeler sağladığı ve bunun sonucunda, \%50'lik bir iyileşme artışı ve yaklaşık olarak 1.6 kat iyileşme sağlandığ 1 görülmüştür (Filippov vd., 2016).

\section{Diğer NTE Minerallerinin Flotasyonu}

Apatit, ekonomik NTE konsantrasyonu içeren bir fosfat mineraldir. NTE içeren apatitin endüstriyel olarak işlenmesinde hidroksamatların kullanımı araştıran bir çalışma yoktur. Ancak alkil hidroksamat kullanımı ile apatitin dolomitten ayrılabildiği gösterilmiştir. Bahsedilen çalışmada adsorpsiyon mekanizması kemisorpsiyon (mineral yüzeyindeki kalsiyuma bağlanma) olarak tanımlanmıştır (Yu vd., 2016). NTE taşıyan apatitlerin karboksilatlar ile flotasyon sürecinde ise diğer fosfat minerallerine benzer davranışlar sergilediği gösterilmiştir (Beer vd., 2014; Harbi vd., 2011; Houot, 1982).

Niyobatlar, genellikle niyobyum eldesi için kullanılmakta ancak önemli miktarda NTE içermektedir. Hidroksamatlarla flotasyon tepkileri incelenen niyobat mineralleri ile ilgili çalışmalar piroklor, kolumbit ve fergusonit için mevcuttur ve en geniş çapta çalışılmış mineral piroklordur (Gibson vd., 2015). Hem BHA (benzohidroksamik asit) hem de alkil hidroksamatlar kullanılarak bu mineralin yüzdürme işlemi gerçekleştirilebilmiştir. Kolumbit ve fergusonit için flotasyon çalışmaları çok kısıtlı bir aralıkta yapılmıştır. Ancak bu mineraller farklı oranlarda çözünebilir olduklarından ve Nb ile NTE içerdiklerinden dolayı hidroksamik asit ile güçlü kompleks oluşturmaktadırlar. $\mathrm{Bu}$ durum flotasyon için iyi yanıt vermelerini sağlamaktadırlar. Kolumbit ve fergusonit kazanımının kanıtı ise Nechalacho yatağındaki bastnazitin BHA ile flotasyonu sırasında gözlemlenmiştir (Jordens vd., 2016). Sodyum oleat kullanılan Fergusonit flotasyonu ise Fawzy tarafindan incelenmiştir. Flotasyon $\mathrm{pH} 2$ ve 10 arasında çalışılmış ve en yüksek kazanım pH 5 değerinde gerçekleşmiştir. Yazar fergusonitin flotasyon kapasitesini artırmak için Span 80 kullanılmasını önermiştir (Fawzy, 2018).

Diğer NTE mineralleri için kullanılan toplayıcilar Tablo 7'de sunulmaktadır. 
Review article/Derleme makale DOI: 10.29132/ijpas.922811

Tablo 6. Monazit ve ksenotim için kullanılan bastırıcılar

\begin{tabular}{|c|c|c|c|}
\hline Nadir Toprak Minerali & Bastıricılar & Gang & Kaynak \\
\hline \multirow{6}{*}{ Monazit } & Sodyum Silikat & $\begin{array}{l}\text { Silikat gang, tuz mineralleri (florit, } \\
\text { barit, kalsit ve dolomit), demir } \\
\text { mineralleri, zirkon, rutil, şörl ve } \\
\text { staurolit }\end{array}$ & (Jordens vd., 2013) \\
\hline & Sodyum florosilikat & Barit, kalsit, florit & (Bulatovic, 2007b) \\
\hline & Sodyum Sülfür & Zirkon & (Pol'kin vd., 1967) \\
\hline & Sodyum Heksametafosfat & Kalsit & (Zhang \& Honaker, 2018) \\
\hline & Silika Jel & Barit, florit, kalsit & (Che vd., 2003) \\
\hline & Nişastalar & Rutil, ilmenit, zirkon & (Bulatovic, 1999) \\
\hline \multirow{3}{*}{ Ksenotim } & Nişastalar & Rutil, ilmenit, zirkon & (Pereira \& Peres, 1997) \\
\hline & Amilopektin & Zirkon & (Pereira \& Peres, 1997) \\
\hline & Quebracho & Zirkon & (Bulatovic, 2007b) \\
\hline
\end{tabular}


Review article/Derleme makale

DOI: 10.29132/ijpas.922811

Tablo 7. Diğer NTE mineralleri için kullanılan toplayıcılar

\begin{tabular}{|c|c|c|c|c|c|c|c|}
\hline Toplayıcı Türü & Toplayıcı & Mineral & Gang Mineraller & Diğer Kimyasallar & $\mathbf{p H}$ & $\begin{array}{l}\text { Saha } \\
\text { Örneği }\end{array}$ & Referans \\
\hline \multirow{2}{*}{ Hidroksamat } & BHA & Allanit & Kuvars & Demir klorür & 4 & & $\begin{array}{l}\text { (Jordens vd., } \\
2014)\end{array}$ \\
\hline & Alkil & Kollofan & Dolomit & & $2-12$ & & (Yu vd., 2016) \\
\hline \multirow{7}{*}{ Karboksilatlar } & \multirow[t]{2}{*}{ Sodyum oleat } & Allanit & Kuvars & & 7.5 & & $\begin{array}{l}\text { (Jordens vd., } \\
\text { 2014a) }\end{array}$ \\
\hline & & Fergusonit & $\begin{array}{l}\text { Zirkon, kuvars, } \\
\text { feldspat }\end{array}$ & $\begin{array}{l}\text { Span } 80 \text {, sodyum metasilikat, oksalik } \\
\text { asit, sitrik asit }\end{array}$ & 5 & & (Fawzy, 2018) \\
\hline & Oleik Asit & Apatit & İlmenit, Manyetit & Sodyum silikat & 9.5 & $\begin{array}{l}\text { Wadi } \\
\text { Khamal }\end{array}$ & $\begin{array}{ll}\text { Harbi vd., } \\
\text { 2011) }\end{array}$ \\
\hline & Betacol & \multirow{2}{*}{$\begin{array}{l}\text { Apatit, } \\
\text { Senkisit }\end{array}$} & \multirow{2}{*}{ Ankerit, kalsit } & \multirow{2}{*}{$\begin{array}{l}\text { Lignin sülfonat, sodyum karbonat, } \\
\text { sodyum florosilikat }\end{array}$} & \multirow{2}{*}{-} & \multirow{2}{*}{ Songwe } & \multirow{2}{*}{$\begin{array}{l}\text { (Beer } \\
2014)\end{array}$} \\
\hline & CKF30B & & & & & & \\
\hline & \multirow{2}{*}{ Tall yağ1 } & Apatit & \multirow{2}{*}{$\begin{array}{l}\text { Nefelin, feldspat, } \\
\text { klinopiroksen }\end{array}$} & \multirow{2}{*}{ Sodyum silikat } & \multirow{2}{*}{-} & \multirow{2}{*}{ Kola } & \multirow{2}{*}{ (Houot, 1982) } \\
\hline & & Titanit & & & & & \\
\hline Fosforik asitler & Dodesilamin & Allanit & Kuvars & & $4-10$ & & $\begin{array}{l}\text { (Jordens vd., } \\
\text { 2014a) }\end{array}$ \\
\hline
\end{tabular}


Allanitlerin karboksilatlar kullanarak yapılan flotasyon işlemi Jordens ve arkadaşları tarafından incelenmiştir. Çalışmada yüksek sodyum oleat dozajının pH 7 değerinde maksimum geri kazanım meydana getirdiği bulunmuş ve yüksek dozaj $(1 \mathrm{~kg} / \mathrm{t})$ kullanımı gerekli olmuştur (Jordens vd., 2014a). Harada ve arkadaşları tarafından sodyum oleat kullanılarak kolumbit flotasyonu araştırılmıştır. Çalışmada kullanılan kolumbit örneğinin NTE içeriği sunulmamıştır; bununla birlikte $\mathrm{pH}$ değeri 2-10 arasında yüksek geri kazanımlar meydana gelmiş, maksimum geri kazanım $\mathrm{pH} 2$ ve 6-10'da gerçekleşmiştir (Harada vd., 1993). Amin toplayıcılar ile allanit, $\mathrm{pH}$ 4-10 aralığında kazanılabilmektedir. Yine de, kuvars kazanımının ötesine geçmek ve allanit toplayabilmek için yüksek dozajlara ihtiyaç duyulmaktadır (Jordens vd., 2014a).

Grönland'daki Kvanefjeld yatağında bulunan Steenstruspin ve monazitin farklı karboksilat toplayıcıları kullanarak yüzdürülmesi, Sorensen ve Lundgaard tarafından yapılmıştır. Araştırmacılar tarafindan, lantan iyonlarının flotasyon işleminde aktivatör işlevi gördüğü saptanmıştır (Sorensen \& Lundgaard, 1966).

Sodyum oleat kullanımının, öncelikle NTE içeren silikatlı cevherlerin flotasyonunda, hidroksamatlara ve fosforik asit türevlerine kıyasla daha iyi yanıt verdiği saptanmıştır. Fakat NTE içeren karbonat minerallerinin sodyum oleata yanıtına kıyasla silikatlar, çok düşük bir flotasyon performansı göstermiştir (Yang vd., 2015).

\section{NTE FLOTASYON MEKANIZMALARI}

Hidroksamik asitler ve hidroksamat tuzları minerallerin yüzeyinde bulunan metal katyonlarıyla kompleks oluşturan bir grup şelatlayıcı toplayıcıdan oluşmaktadır. Hidroksamat-metal kompleksinin oluşumunda, toplayıcı bünyesindeki $\mathrm{H}^{+}$iyonu ile metal katyonu yer değiştirmektedir. Yer değiştirmiş metal katyonu, hidroksamat yapısındaki karbonil grubunun oksijeni ile "halka kapanması" (ring closure) gerçekleştirir. Hidroksamat grubu ve hidroksamat-metal kompleksinin bir görüntüsü Şekil 1'de sunulmuştur (Cao vd., 2019; Cui vd., 2012; Espiritu vd., 2018; Gao vd., 2018; Hope vd., 2010; Li vd., 2018; Pradip \& Fuerstenau, 1983; Zhang \& Honaker, 2018).

Metal katyonuna bağlı olarak oluşan hidroksamat-metal kompleksinin kararlığı değişmektedir. En kararlı komplekslerini $\mathrm{Fe}^{+3}, \mathrm{Al}^{+2}$,
$\mathrm{Cu}^{+2}, \mathrm{Cr}^{+3}$ ve $\mathrm{Pb}^{+2}$ ile oluştururlar, bahsedilen metallerin hemen arkasından ise NTE gelmektedir. En zayıf komplekslerini ise alkali toprak metalleri ile oluştururlar. Dolayısıyla bu toplayıcılar, NTE minerallerinin barit ve kalsit içeren yapılardan ayrılması için bir olanak sunmaktadırlar (Fuerstenau, 2005; Khairy vd., 1996; Khalil \& Fazary, 2004; Sastri vd., 2003). Seçiciliğin bir göstergesi olarak, oluşan kompleksin kararlık sabiti önemlidir; yani kararlılık sabitleri arasındaki fark arttıkça seçicilik de artmaktadir (Pavez \& Peres, 1993a; Pradip \& Fuerstenau, 1983). Hidroksamat topalyıcilar mineral yüzeyindeki metal katyonları ile iki şekilde etkileşime girmektedir. Bunlardan biri kemisorpsiyon diğeri yüzey reaksiyonlarıdır (Pradip \& Fuerstenau, 1983). Kemisorpsiyon, mineral kafesi içerisindeki metal katyonunun şelatlanma reaksiyonu ile gerçekleşir. Yüzey reaksiyonları ise, kafes yapısı içindeki katyonların hidrolizi ile çözelti içerisinde hidroksil kompleksleri oluşması ve bu komplekslerin tekrar mineral yüzeyine tutunması veya mineral yüzeyinde çökmesi ile hidroksamat iyonlarının bağlanabileceği alanlar yaratmasıdır. Ayrıca mineral çözünürlügünün artması ile adsorpsiyon kinetiği de hızlanmaktadır (Assis vd., 1996). Ayrica baz1 çalışmalarda mineral içerisindeki O-O bağ uzunluğunda hangi mineralin şelatlanma reaksiyonu göstereceğini tayin edebileceği belirtilmiştir, hikdroksamat ile benzer O-O bağ uzunluğuna sahip olan minerallerin oluşturacağı komplekslerin daha kararlı olacağı saptanmıştır (Gao vd., 2018; Pradip \& Fuerstenau, 1983).

Nadir toprak elementlerinin hidroksamatlar ile flotasyonu konusunda ise, en büyük etkiyi Ce elementi yapmaktadır. Bastnazit ve monazit içerisindeki en çok bulunan NTE olan Ce, toplayıcılar ile en çok etkileşime giren NTE'dir. Bu sebeple toplayıcıların adsorpsiyon mekanizmasını anlamak için çözelti ortamında oluşabilecek $\mathrm{Ce}$ komplekslerinin toplayıcılar ile etkileşimi üzerine yoğunlaşılmıştır. Bugüne kadar yapılmış mekanizma belirleme çalışmaları hidroksillenmiş $\mathrm{Ce}$ kompleksleri olan $\mathrm{Ce}(\mathrm{OH})^{+2}$ ve $\mathrm{Ce}(\mathrm{OH})_{2}{ }^{+}$ bileşiklerinin mineral yüzeyinde toplayıcılar için yüzey sağladığını saptamışlardır (Jordens vd., 2014b; Sarvaramini vd., 2016; Zhang \& Edwards, 2012). Yoğunluk fonksiyonel teorisi kullanılarak, katıhal fiziği ve kuantum mekanikleri yardımıyla uygulanan simülasyon çalışmalarında ise, heptilhidroksamik asit (HHA) ile bahsedilen hidroksillenmiş $\mathrm{Ce}$ 
komplekslerinin etkileşimi incelenebilmiștir. İnceleme sonucu mineral yüzeyinde, $\left[\mathrm{Ce}(\mathrm{OH})(\mathrm{HHA})_{3}(\mathrm{H} 2 \mathrm{O})\right]^{-}$ve $\left[\mathrm{Ce}(\mathrm{OH})_{2}(\mathrm{HHA})_{3}\right]^{-2}$ oluşumu saptanmıştır (Sarvaramini vd., 2016).

Çözünürlük durumuna göre hidroksamat toplayıcıların minerallerle etkileşimi farklılık göstermektedir. Bastnazit gibi yarı çözünür mineraller için yüzey çökelmelerine adsorbe olurken monazit gibi düşük çözünürlüğe sahip minerallerde kemosorsiyon mekanizması ile adsorbe olurlar. Yarı çözünür mineraller için endotermik bir adsorpsiyon geçerliyken, düşük çözünürlüğe sahip mineraller için ekzotermik bir adsorpsiyon gözlemlenir. Monazit gibi mineraller için, toplayıcı dozajı tek katmanlı kaplanma seviyesinin üzerine çıkarsa toplayıcı yüzey çökelmelerine adsorbe olur ve endotermik hale geçiş yapar. Mineral yüzeyinin toplayıc1 ile kaplanmasindan sonra sisteme dahil olan toplayıcıların mineral yerine yüzeydeki toplayıcı partikülleri ile etkileşime girmesi bu durumun sebebidir (Gupta, 2013; Pradip \& Fuerstenau, 1985, 1991). İki mekanizma da pozitif entropi değişimine sahiptir. Dolayısıyla entropi tarafindan yönetilirler. Pozitif entropi değişiminin bir sonucu olarak her mineral için sıcaklığın artırılması, kazanımı ve adsorpsiyon yoğunluğunu artırmaktadır (Gupta, 2013; Pavez \& Peres, 1993a; Pradip \& Fuerstenau, 1991).

Literatürde yapılan çalışmalarda, sıcaklığın bastnazit için kararlı hale getirici bir etkisi olduğu belirlenmiştir (Li vd., 2018). Bunun yanısıra kullanilan potasyum oktil hidroksamat $(\mathrm{POH})$ ile oda sıcaklığında kalsit, barit ve bastnazit flotasyonu yapıldığında, üç minerale de farklı serbest enerjiler ile adsorpsiyon gerçekleştiği saptanmıştır. Elde edilen farkl1 serbest enerjiler, termodinamik olarak bastnazitin daha kararlı bir adsorplanma gösterdiğini kanıtlamıştır (Gupta, 2013). Sicaklık artışı ile birlikte,

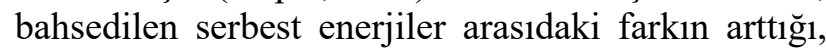
dolayısıyla seçiciliğin de arttığı saptanmıştır (Gupta, 2013; Li vd., 2018; Pavez \& Peres, 1993a; Pradip \& Fuerstenau, 1985, 1991).

Hidroksamat toplayıcıların artan sicaklıkla nadir toprak metali flotasyonuna zarar verdiği örnekler de mevcuttur. Örneğin sıcaklık artışı OHA (oktil hidroksamik asit) kullanımında pozitif etki etmesine rağmen, ticari Flotinor V3759 kullanımında monazit flotasyon verimini düşürmektedir (Pavez \& Peres, 1993a). Maoniuping bastnazit cevheri üzerine yapılan bir çalışmada da, $35^{\circ} \mathrm{C}$ sıcaklığa kadar küçük artışlar gözlense de, daha yüksek sıcaklıklarda tenör değerinde düşüşlere sebep olmuştur (Wang vd., 2012).

Pavez ve Peres sicaklığın OHA kullanımında pozitif etkisini tespit etmelerine rağmen ticari hidroksamat Flotinor V3759 kullanımında sıcaklık artışının monazit flotasyon verimini düşürürken, zirkon ve rutil verimlerini ise nispeten artırmıştır (Pavez \& Peres, 1993a). Wang vd., Maoniuping bastnazit cevherini hidroksamat toplayıciyla flote ettiğinde, artan sicaklığın $\left(35^{\circ} \mathrm{C}\right.$ 'e kadar) tenör ve verimde küçük artışlara sebep olduğunu bulmuşlardır. Buna rağmen sıcaklığın bu değerlerin üzerinde artması bastnazit verimine zarar vermiş olup, $50^{\circ} \mathrm{C}$ 'nin üzerinde ise tenör değeri düşmüştür (Wang vd., 2012).

Bazı çalışmalarda da alkil hidroksamat zincir uzunluğunun etkisi incelemiş olup, hidrokarbon zinciri uzadıkça flotasyon performasını artacağı önerilmiştir (Palmer vd., 1973; Sreenivas \& Padmanabhan, 2002). Öteyandan, diğer çalışmalarda karbon zinciri C9'dan daha uzun olan hidroksamatların daha düşük flotasyon performansına sahip olduğunu tespit edilmiştir [107]. Günümüzde yapılan laboratuvar çalışmaları hidroksamat toplayıcılarla yapilan mineral flotasyonunda alkil hidroksamatlara yoğunlaşmış olsa da modifiye edilmiş bir naftil hidroksamat olan $\mathrm{H}_{205}$ ile Çin'de bastnazit cevherinden NTO üretimi sağlanmaktadır (Jordens vd., 2013; Li vd., 1988; Zhang \& Edwards, 2012). C5-C9 alkil hidroksamat karışımı ve $\mathrm{H}_{205}$ Bayan Obo cevherinin flotasyonunda karşılaştırılmıştır. Yapılan çalışmaya göre, verim ve tenör değerlerini artırmak için yüksek dozajda $\mathrm{H}_{205}$ kullanımı gerekmesine rağmen, sodyum florosilikat bastırıcısının kullanılmaması bu toplayıcının avantaj1 olarak belirtilmiştir. Bu çalışma ayrıca, daha düşük verim değerleriyle de olsa; naftil toplayıcının alkil hidroksamatlardan daha büyük seçicilik gösterdiğini ortaya atmaktadır (Palmer vd., 1973).

Nadir toprak minerallerinin hidroksamik asit toplayıcılarına tepkisi sadece toplayıcı yapısına göre değil, aynı zamanda mineral tipine göre de değişmektedir. Çalışmalar karbonat, fosfat ve niyobat minerallerinin çok fazla zorluk çıkarmadan yüzmeye meyilli olduğunu ama silikat minerallerinin çok yüksek dozajlarda toplayıcı kullanımı ya da toplayıc1 kullanımı olmadan çok iyi sonuç vermediğini göstermektedir (Marion vd., 2020). 


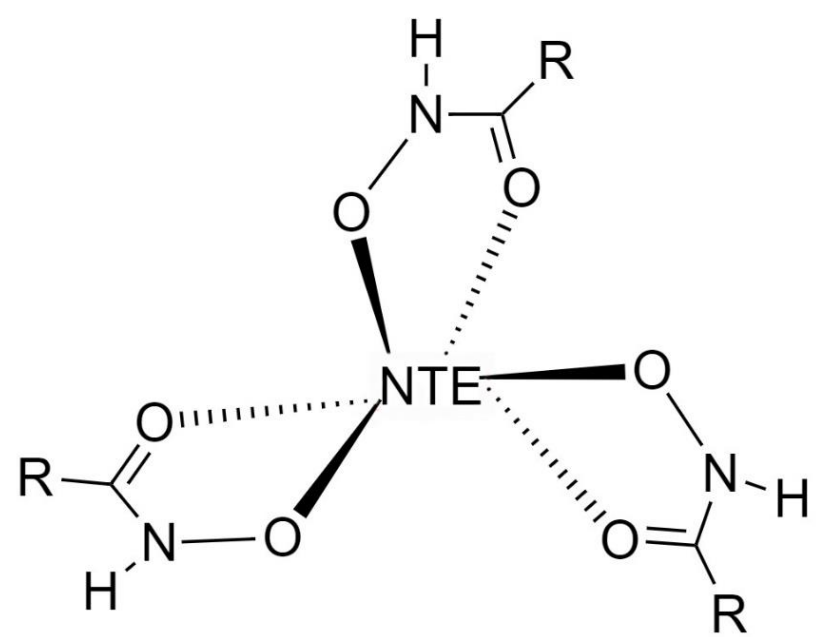

Şekil 1. Hidroksamat-metal kompleksinin kimyasal yapısı (Orlowska vd., 2016)

\section{SONUÇ}

Nadir toprak elementleri, ileri teknoloji uygulamalarda sıklıkla kullanılmasından dolayı gün geçtikçe daha da önemli bir hale gelmektedir. Günümüzde kullandığımız birçok elektronik cihazın içerisinde az miktarda da olsa kullanılmaktadırlar. Bunlar dışında katalizörler, şarj edilebilir piller ve özellikle mıknatıslarda kullanımları bu elementlere olan talebi artırmaktadır. Artan talep ve kısitlı tedarik doğrultusunda, Avrupa Komisyonu Kritik Hammaddeler raporunda en kritik element gruplarından biri olarak belirlenmiştir. Kritiklik düzeyinin yüksek olması sebebiyle, bu elementlerin ayrılmasındaki temel proseslere hakimiyet sağlanması önümüzdeki yıllar için önemlidir. İşletme verimliliklerini yükseltmek ve ileri saflaştırma aşamalarında oluşacak atık miktarlarını minimize etmek için nadir toprak elementlerinin fiziksel yöntemlerle zenginleştirme ve flotasyonu üzerine detaylı bir inceleme yapılmıştır.

Yapılan incelemeler sonucunda NTE minerallerinin flotasyonu literatürde önemli bir yer tutmaktayken, diğer yöntemler üzerine detaylandırılmış çalışmalara daha az rastlanmaktadır. Zenginleştirme yöntemleri açısından incelendiğinde NTE minerallerinin düşük boyutlarda serbestleşmesi nedeniyle flotasyon dışındaki yöntemler yalnızca ön zenginleştirme aşamasında kullanılmaktadır. $\mathrm{Bu}$ sebeple daha ince tane boyutlarında zenginleștirme imkanı taniyan flotasyon ve hidrometalurjik yöntemler tercih edilmektedir. Ayrıca kullanılan fiziksel zenginleştirme yöntemleri ve flotasyon şemaları, cevher yapısı içindeki diğer minerallere bağlı olduğundan genel bir akış şeması önerilememektedir.

Ayrıca NTE üretimi yapılabilen mineraller üzerine sıklıkla çalışılmış iken, alternatif olarak üretimde kullanılabilecek mineraller üzerine yetersiz bir literatür sunulabilmektedir. Yapılacak yeni çalışmalarda, alternatif NTE mineralleri ve alternatif fiziksel zenginleştirme yöntemleri üzerine durulması yazarlar tarafindan önerilmektedir.

Detaylı incelemeler sonucunda bastnazit minerali için flotasyon öncesi gravitik ve manyetik ayırma yöntemlerinin kullanılabildiği görülmüştür. Bastnazit gibi yarı çözünür minerallerin yüzey özelliklerinin benzer olmasından dolayı seçimli flotasyon güçleşmektedir. Bunun yanısıra çalışmalarda elde edilen $\mathrm{pH}$ değerleri birbirleri ile uyumsuzluk göstermektedir. Uyumsuzluk sebebi olarak bastnazitin birlikte bulunduğu minerallerin ve tenörünün değişiklik göstermesidir. Bastnazit flotasyonunda toplayıcı olarak hidroksamatlar ve yağ asitlerinin etkili olabileceği yapılmış çalışmalardan anlaşılmaktadır. Monazit ve ksenotim mineralleri birbirleri ile benzer yapida olmaları sebebiyle, fiziksel zenginleştirme ve flotasyon davranışları da benzeşmektedir. Manyetik ayırma, monazit için bastnazitten daha sik kullanılmaktadır. Flotasyon aşamasında ise hidroksamat toplayıcılara da yanıt vermelerine rağmen yağ asitleri ile daha iyi sonuçlar elde edilmektedir. 
Flotasyon çalışmalarında tek mineral kullanılan çalışmalar, cevher içeriklerinde benzer tepkiler verebilecek mineraller olmasi durumunda yanıltic1 olabilmektedir. Ayrıca kullanılan bastırıcıların da yüzdürülmek istenen NTE minerallerine karşı etkili olduğu yapılmış çalışmalarda kanıtlanmıştır. Dolayısıyla NTE minerallerinin fiziksel zenginleştirmesi ve flotasyonu için, günümüze kadar yapılmış çalışmalarla genel bir akış şeması sunulamamakta fakat en önemli noktanın başlangıçta cevher içerisindeki bütün minerallerin doğru tanımlanması olduğu belirtilebilmektedir. Doğru mineral tanımlaması yapıldıktan sonra elde edilecek sonuçlar kinetik modellemeler veya günümüzde gittikçe önemli bir hale gelen yapay sinir ağları yardımıyla genel bir akış şeması oluşturulmasına katkıda bulunabilir.

\section{TEŞEKKÜR}

Yazarlar bu çalışmanın yazılması aşamasında destek sağlayan Maden Tetkik ve Arama Genel Müdürlüğü çalışanları Emrecan Dündar ve Ufuk Özdemir'e teşekkürlerini sunmaktadırlar.

\section{ÇIKAR ÇATIŞMASI BEYANI}

Yazar/ Yazarlar bu makale ile ilgili herhangi bir çıkar çatışması bildirmemektedir.

\section{ARASTIRMA VE YAYIN ETİĞİ BEYANI} Yazar/Yazarlar bu çalışmanın araştırma ve yayın etiğine uygun olduğunu beyan eder.

\section{KAYNAKLAR}

Abaka-Wood, G. B., Addai-Mensah, J., \& Skinner, W. (2017). A study of flotation characteristics of monazite, hematite, and quartz using anionic collectors. International Journal of Mineral Processing, 158, 55-62. https://doi.org/10.1016/j.minpro.2016.11.012

Abeidu, A. M. (1972). The separation of monazite from zircon by flotation. Journal of The Less-Common Metals 29(2),

113-119. https://doi.org/10.1016/0022-5088(72)90181-6

Andrews, W., Collins, D., \& Hollick, C. T. (1990). The Flotation of Rare Earths-A Contribution to Industrial Hygien. The AusIMM Annual Conference.

Assis, S. M., Montenegro, L. C. M., \& Peres, A. E. C. (1996). Utilisation of hydroxamates in minerals froth flotation. Minerals Engineering, 9(1), 103-114. https://doi.org/10.1016/0892-6875(95)00134-4
Azizi, D., Larachi, F., \& Latifi, M. (2016). Ionic-liquid collectors for rare-earth minerals flotation-Case of tetrabutylammonium bis(2-ethylhexyl)-phosphate for monazite and bastnäsite recovery. Colloids and Surfaces A: Physicochemical and Engineering Aspects, 506, 74-86. https://doi.org/10.1016/j.colsurfa.2016.06.011

Balaram, V. (2019). Rare earth elements: A review of applications, occurrence, exploration, analysis, recycling, and environmental impact. Geoscience Frontiers, 10(4), 1285-1303. https://doi.org/10.1016/j.gsf.2018.12.005

Beer, G., Dawes, W., Brady, A. E., Bryson, M., \& Sehlotho, N. (2014). Development of a Metallurgical Flow Sheet for the Songwe Hill Rare Earth Project in Malawi. Conference of Metallurgists.

Boulanger, J. F., Bazin, C., \& Turgeon, K. (2019). Effect of depressants and temperature on bastnaesite and monazite flotation separation from a canadian rare earth element (REE) ore. Minerals, 9(4), 225. https://doi.org/10.3390/min9040225

Bulatovic, S. M. (1999). Use of organic polymers in the flotation of polymetallic ores: A review. Minerals Engineering, 12(4), 341-354. https://doi.org/10.1016/S0892-6875(99)00015-1

Bulatovic, Srdjan M. (2007a). Collectors. In Handbook of Flotation Reagents (5-41). Elsevier. https://doi.org/10.1016/b978-044453029-5/50011-3

Bulatovic, Srdjan M. (2007b). Interaction of Organic Regulating Reagents. In Handbook of Flotation Reagents (185-202). Elsevier. https://doi.org/10.1016/b978-044453029-5/50018-6

Bulatovic, Srdjan M. (2007c). Modifying Reagents. In Handbook of Flotation Reagents (53-79). Elsevier. https://doi.org/10.1016/b978-044453029-5/50013-7

Bulatovic, Srdjan M. (2010). Flotation of REO Minerals. In Handbook of Flotation Reagents: Chemistry, Theory and Practice (151-173). Elsevier. https://doi.org/10.1016/b978-0-444-53082-0.00024$\mathrm{x}$

Cao, Zhao, Cao, Y., Qu, Q., Zhang, J., \& Mu, Y. (2019). Separation of bastnäsite from fluorite using ethylenediamine tetraacetic acid as depressant. Minerals Engineering, 134, 134-141. https://doi.org/10.1016/j.mineng.2019.01.030

Chan, T. N. (1992). A new beneficiation process for the treatment of supergene monazite ore. Rare Earths: Extraction, Preparation and Applications: Proceedings of a Symposium held by TMS and AusIMM during the TMS Annual Meeting in San Diego, California March 1-5, 77-94.

Che, L., Yu, Y., \& Wang, X. (2003). Study Flotation of Rare Earth Minerals By New Collector DH. XXII International Mineral Processing Congress, October, 1143-1150. 
Cheng, T. W., Holtham, P. N., \& Tran, T. (1993). Froth flotation of monazite and xenotime. Minerals Engineering, 6(4), 341-351. https://doi.org/10.1016/0892-6875(93)90014-E

Cheng, T. W., Partridge, A. C., Tran, T., \& Wong, P. L. M. (1994). The surface properties and flotation behaviour of xenotime. Minerals Engineering, 7(9), 1085-1098. https://doi.org/10.1016/08926875(94)90001-9

Chi, R., Xu, S., Zhu, G., Xu, J., \& Qiu, X. (2001). Beneficiation of Rare Earth Ore in China. Içinde Anjier JL (Ed.), Light Metals. The Minerals, Metals \& Materials Society.

Choi, H. S., \& Whang, K. U. (1963). Surface properties and floatability of zircon. CIM Bulletin, 56, 466-468.

Cui, H., \& Anderson, C. G. (2017a). Alternative flowsheet for rare earth beneficiation of Bear Lodge ore. Minerals Engineering, 110, 166-178. https://doi.org/10.1016/j.mineng.2017.04.016

Cui, H., \& Anderson, C. G. (2017b). Fundamental Studies on the Surface Chemistry of Ancylite, Calcite, and Strontianite. Journal of Sustainable Metallurgy, 3(1), 48-61. https://doi.org/10.1007/s40831-0160097-x

Cui, J., Hope, G. A., \& Buckley, A. N. (2012). Spectroscopic investigation of the interaction of hydroxamate with bastnaesite (cerium) and rare earth oxides. Minerals Engineering, 36-38, 91-99. https://doi.org/10.1016/j.mineng.2012.03.001

Deng, T., \& Hill, G. (2014). Flotation of REE Bearing Minerals from Silicate and Carbonate Host Deposits. In Proceeding of the 53rd Annual Conference of Metallurgists.

Espiritu, E. R. L., da Silva, G. R., Azizi, D., Larachi, F., \& Waters, K. E. (2018). The effect of dissolved mineral species on bastnäsite, monazite and dolomite flotation using benzohydroxamate collector. Colloids and Surfaces A: Physicochemical and Engineering Aspects, 539, 319-334. https://doi.org/10.1016/j.colsurfa.2017.12.038

Espiritu, E. R. L., Naseri, S., \& Waters, K. E. (2018). Surface chemistry and flotation behavior of dolomite, monazite and bastnäsite in the presence of benzohydroxamate, sodium oleate and phosphoric acid ester collectors. Colloids and Surfaces A: Physicochemical and Engineering Aspects, 546, 254-265.

https://doi.org/10.1016/j.colsurfa.2018.03.030

Espiritu, E. R. L., \& Waters, K. E. (2018). Flotation studies of monazite and dolomite. Minerals Engineering, 116 , 101-106. https://doi.org/10.1016/j.mineng.2017.02.010

Falconer, A., (2003). Gravity separation: old technique/new methods. Physical Separation in
Science and Engineering 12 (1), 31-48. https://doi.org/10.1080/1478647031000104293

Fawzy, M. M. (2018). Surface characterization and froth flotation of fergusonite from Abu Dob pegmatite using a combination of anionic and nonionic collectors. Physicochemical Problems of Mineral Processing, 54(3), 677-687. https://doi.org/10.5277/ppmp1865

Ferron, C. J., Bulatovic, S. M., \& Salter, R. S. (1991). Beneficiation of Rare Earth Oxide Minerals. Materials Science Forum, 70-72, 251-270. https://doi.org/10.4028/www.scientific.net/msf.7072.251

Filippov, L. O., Dehaine, Q., \& Filippova, I. V. (2016). Rare earths (La, Ce, $\mathrm{Nd}$ ) and rare metals $(\mathrm{Sn}, \mathrm{Nb}, \mathrm{W})$ as by-products of kaolin production - Part 3: Processing of fines using gravity and flotation. Minerals Engineering, 95, 96-106. https://doi.org/10.1016/j.mineng.2016.06.004

Fuerstenau, M. C. (2005). Chelating agents as flotation collectors. Proceedings of the Jan D. Miller Symposium - Innovations in Natural Resource Processing, 2005, 33-56.

Gao, Y., Gao, Z., Sun, W., Yin, Z., Wang, J., \& Hu, Y. (2018). Adsorption of a novel reagent scheme on scheelite and calcite causing an effective flotation separation. Journal of Colloid and Interface Science, 512 , 39-46. https://doi.org/10.1016/j.jcis.2017.10.045

Gee, B., Holtham, P., Dunne, R., Gregory, S., (2005). Recovery of fine gold particles using a Falcon 'B' separator. In: International Symposium on the Treatmen of Gold Ores. pp. 3 - 15

Gibson, C. E., Kelebek, S., \& Aghamirian, M. (2015). Niobium oxide mineral flotation: A review of relevant literature and the current state of industrial operations. In International Journal of Mineral Processing (C. 137, 82-97). https://doi.org/10.1016/j.minpro.2015.02.005

Goode, J. R. (2014). The recovery of rare earths, uranium and pyrite from Pele Mountain's proposed Eco Ridge mine project. COM 2014, 1-11.

Gupta, S. P. (Ed.). (2013). Hydroxamic Acids: A Unique Family of Chemicals with Multiple Biological Activities. Springer, Heidelberg.

Guy, P. J., Bruckard, W. J., \& Vaisey, M. J. (2000). Beneficiation of Mt weld rare earth oxides by gravity concentration, flotation and magnetic separation. Australasian Institute of Mining and Metallurgy Publication Series, 6, 197-206.

Güneş, H., Obuz, H. E., Oğur, E., Çapraz, F., \& Alkan, M. (2018). Rare-Earth Elements Recovery from Nd-Fe$B$ Hard Magnets by Hydrometallurgical Processes In Extraction 2018 (2837-2843). Springer, Cham. https://doi.org/10.1007/978-3-319-95022-8_239 
Harada, T., Owada, S., Takiuchi, T., \& Kurita, M. (1993). A Flotation Study for Effective Separation of the Heavy Mineral Sands. Australasian Institute of Mining and Metallurgy Publication Series, May, 1017-1024.

Harbi, H. M., Eldougdoug, A. A., \& El-Shahawi, M. S. (2011). Mineral processing and extraction of rare earth elements from the wadi khamal nelsonite ore, northwestern saudi arabia. Arabian Journal of Geosciences, 4(3-4), 353-363. https://doi.org/10.1007/s12517-009-0061-1

Herrera-Urbina, R., Pradip, \& Fuerstenau, D. W. (2013). Electrophoretic mobility and computations of solidaqueous solution equilibria for the bastnaesite- $\mathrm{H} 2 \mathrm{O}$ system. Minerals and Metallurgical Processing, 30(1), 18-23. https://doi.org/10.1007/bf03402337

Hope, G. A., Woods, R., Parker, G. K., Buckley, A. N., \& McLean, J. (2010). A vibrational spectroscopy and XPS investigation of the interaction of hydroxamate reagents on copper oxide minerals. Minerals Engineering, 23(11-13), 952-959. https://doi.org/10.1016/j.mineng.2010.03.012

Houot, R. (1982). Beneficiation of phosphatic ores through flotation: Review of industrial applications and potential developments. International Journal of Mineral Processing, 9(4), 353-384. https://doi.org/10.1016/0301-7516(82)90041-2

Houot, Robert, Cuif, J.-P., Mottot, Y., \& Samama, J.-C. (1991). Recovery of Rare Earth Minerals, with Emphasis on Flotation Process. Materials Science Forum, 70-72, 301-324. https://doi.org/10.4028/www.scientific.net/msf.7072.301

Hyung, S., \& Ki, U. (1963). Mechanism of Collector Adsorption on Monazite. Journal of the Korean Chemical Society, 7, 91-95.

Ito, S., Yotsumoto, H., \& Sakamoto, H. (1991). Magnetic separation of monazite and xenotime. Proceedings of the International Conference on Rare Earth Minerals and Minerals for Electronic Uses, 279299.

Jensen, J., \& Mackintosh, A. R. (1991). Rare Earth Magnetism: Structures and Excitations. Clarendon Press.

Jeong, C., \& Cho, H. (2014). Concentration of Rare Earth Elements by Flotation of REE Ores from Mushgai , Khudag Area, Mongolia. IMPC 2014, 1-9.

Jha, A. (2014). Rare Earth Materials: Properties and Applications, 371, CRC Press, Boca Raton. https://doi.org/10.1201/b17045

Jordens, A., Cheng, Y. P., \& Waters, K. E. (2013). A review of the beneficiation of rare earth element bearing minerals. In Minerals Engineering (97-114). Elsevier https://doi.org/10.1016/j.mineng.2012.10.017
Jordens, A., Marion, C., Grammatikopoulos, T., Hart, B., \& Waters, K. E. (2016). Beneficiation of the Nechalacho rare earth deposit: Flotation response using benzohydroxamic acid. Minerals Engineering, 99, $158-169$. https://doi.org/10.1016/j.mineng.2016.08.024

Jordens, A., Marion, C., Kuzmina, O., \& Waters, K. E. (2014a). Physicochemical aspects of allanite flotation. Journal of Rare Earths, 32(5), 476-486. https://doi.org/10.1016/S1002-0721(14)60096-X

Jordens, A., Marion, C., Kuzmina, O., \& Waters, K. E. (2014b). Surface chemistry considerations in the flotation of bastnäsite. Minerals Engineering, 66, 119-129. https://doi.org/10.1016/j.mineng.2014.04.013

Jordens, A., McCarthy, S., \& Waters, K. E. (2014). The effect of activating ions on the adsorption of a benzohydroxamic acid collector onto a rare earth silicate. COM 2014, 1-12.

Jordens, A., Zhiyong, Y., \& Cappuccitti, F. (2016). The application of florrea 8920, a new hydroxamatebased flotation collector for the flotation of rare earth minerals. IMPC 2016 - 28th International Mineral Processing Congress Proceedings.

Khairy, E., Shoukry, M., Khalil, M., \& Mohamed, M. (1996). Metal complexes of salicylhydroxamic acid: equilibrium studies and synthesis. Transition Metal Chemistry, 21, 176-180.

Khalil, M. M., \& Fazary, A. E. (2004). Potentiometric studies on binary and ternary complexes of di- and trivalent metal ions involving some hydroxamic acids, amino acids, and nucleic acid components. Monatshefte fur Chemie, 135(12), 1455-1474. https://doi.org/10.1007/s00706-004-0243-1

Krishnamurthy, N., \& Gupta, C. K. (2015). Extractive metallurgy of rare earths. 869, CRC press, Boca Raton.

Li, F., Wang, J., \& Zeng, X. (1988). A Process on the Recovery of RE Minerals With a Chelating Collector. Içinde R. Bautista \& M. Wong (Ed.), Rare Earths, Extraction, Preparation and Applications (71-79). The Minerals, Metals and Materials Society.

Li, M., Gao, K., Zhang, D., Duan, H., Ma, L., \& Huang, L. (2018). The influence of temperature on rare earth flotation with naphthyl hydroxamic acid. Journal of Rare Earths, 36(1), 99-107. https://doi.org/10.1016/j.jre.2017.07.004

Lucas, J., Lucas, P., Le Mercier, T., Rollat, A., \& Davenport, W. (2014). Rare Earths: Science, Technology, Production and Use, 370, Elsevier, https://doi.org/10.1016/C2012-0-02577-X

Luo, J., \& Chen, X. (1984). Research into the recovery of high-grade rare-earth concentrate from Baotou complex iron ore, China. Mineral Processing and 
Extractive Metallurgy: papers presented at the international conference organized by the Institute of Mining and Metallurgy and the Chinese Society of Metals held in Kunming, Yunnan Province, PRC from Oct. 27 to Nov. 3, 663-675.

Maden Tetkik ve Arama Genel Müdürlüğü. (2017). Dünyada ve Türkiye'de Nadir Toprak Elementleri.

Marion, C., Li, R., \& Waters, K. E. (2020). A review of reagents applied to rare-earth mineral flotation. Advances in Colloid and Interface Science, 279, 102142. https://doi.org/10.1016/j.cis.2020.102142

McEwen, R., Hansen, G. W., \& Lee, G. F. (1976). Singlestage flotation of alkali feldspars, ilmenite, rutile, garnet, and monazite, with mixed cationic/anionic collectors. Trans Soc Min Eng AIME, 260(1), 97100.

Morrice, E., \& Wong, M. M. (1982). Flotation of Rare Earths from Bastnasite Ore, US Department of the Interior, Bureau of Mines, Report of investigation 8689, 12.

Moustafa, M. I., \& Abdelfattah, N. A. (2010). Physical and Chemical Beneficiation of the Egyptian Beach Monazite. Resource Geology, 60(3), 288-299. https://doi.org/10.1111/j.1751-3928.2010.00131.x

Obuz, H. E., Günes, H., Kara, A., Ugurluer, D., Babuccuoglu, Y., \& Alkan, M. (2018). Leaching Kinetics of Rare-Earth Elements from Complex Ores by Acidic Solutions In Extraction 2018 (2391-2398). Springer, Cham. https://doi.org/10.1007/978-3-31995022-8_201

Orlowska, E., Roller, A., Wiesinger, H., Pignitter, M., Jirsa, F., Krachler, R., Kandioller, W., \& Keppler, B. K. (2016). Benzoic hydroxamate-based iron complexes as model compounds for humic substances: Synthesis, characterization and algal growth experiments. RSC Advances, 6(46), 4023840249. https://doi.org/10.1039/c5ra25256c

Owens, C. L., Nash, G. R., Hadler, K., Fitzpatrick, R. S., Anderson, C. G., \& Wall, F. (2018). Zeta potentials of the rare earth element fluorcarbonate minerals focusing on bastnäsite and parisite. In Advances in Colloid and Interface Science (152-162). https://doi.org/10.1016/j.cis.2018.04.009

Özbayoğlu, G., \& Atalay, M. Ü. (2000). Beneficiation of bastnaesite by a multi-gravity separator. Journal of alloys and compounds, 303, 520-523. https://doi.org/10.1016/S0925-8388(00)00639-3

Palmer, B. R., Gutierrez B, G., \& Fuerstenau, M. C. (1973). Mechanisms involved in the flotation of oxides and silicates with anionic collectors Part I. Trans Soc Min Eng AIME, 258(3), 257-263.

Pavez, O., Brandao, P. R. G., \& Peres, A. E. C. (1996). Adsorption of oleate and octyl-hydroxamate on to rare-earths minerals. Minerals Engineering, 9(3),
$357-366$. 6875(96)00020-9

https://doi.org/10.1016/0892-

Pavez, O., \& Peres, A. E. C. (1993a). Effect of sodium metasilicate and sodium sulphide on the floatability of monazite-zircon-rutile with oleate and hydroxamates. Minerals Engineering, 6(1), 69-78. https://doi.org/10.1016/0892-6875(93)90164-I

Pavez, O., \& Peres, A. E. C. (1993b). Flotation of Monazite-Zircon-Rutile with Sodium Oleate and Hydroxamates. XVIII International Mineral Processing Congress, 1007-1013.

Pavez, O., \& Peres, A. E. C. (1994). Technical note bench scale flotation of a brazilian monazite ore. Minerals Engineering, $\quad 7(12)$, 1561-1564. https://doi.org/10.1016/0892-6875(94)90047-7

Pereira, C. A., \& Peres, A. E. C. (1997). Flotation concentration of a xenotime pre-concentrate. Minerals Engineering, 10(11), 1291-1295. https://doi.org/10.1016/s0892-6875(97)00115-5

Pol'kin, S. I., Ilie, P., Solnyshkin, V. I., \& Zakharov, A. E. (1967). Selective Desorption of Sodium Oleate from Pyrochlore, Zircon and Monazite by Sodium Sulfide. In Flotation Properties of Rare Metal Minerals (4656).

Pradip, \& Fuerstenau, D. W. (1983). The adsorption of hydroxamate on semi-soluble minerals. Part I: Adsorption on barite, Calcite and Bastnaesite. Colloids and Surfaces, 8(2), 103-119. https://doi.org/10.1016/0166-6622(83)80079-1

Pradip, \& Fuerstenau, D. W. (1985). Adsorption of hydroxamate collectors on semisoluble minerals Part II: Effect of temperature on adsorption. Colloids and Surfaces, 15(C), 137-146. https://doi.org/10.1016/0166-6622(85)80061-5

Pradip, \& Fuerstenau, D. W. (1991). The role of inorganic and organic reagents in the flotation separation of rare-earth ores. International Journal of Mineral Processing, 32(1-2), 1-22. https://doi.org/10.1016/0301-7516(91)90016-C

Pryor, E. J. (1965). Mineral Processing. 844, Springer, Dordrecht.

Ren, Jun, Song, S., Lopez-Valdivieso, A., \& Lu, S. (2000). Selective flotation of bastnaesite from monazite in rare earth concentrates using potassium alum as depressant. International Journal of Mineral Processing, 59(3), 237-245. https://doi.org/10.1016/S0301-7516(99)00075-7

Ren, Jun, Wang, W., Luo, J., Zhou, G., \& Tang, F. (2003). Progress of flotation reagents of rare earth minerals in China. Journal of Rare Earths, 21(1), 1-8.

Roskill. (2021). Rare Earths - Market Report. https://roskill.com/market-report/rare-earths/

Sarvaramini, A., Azizi, D., \& Larachi, F. (2016). Hydroxamic acid interactions with solvated cerium hydroxides in the flotation of monazite and 
bastnäsite-Experiments and DFT study. Applied Surface Science, 387, 986-995. https://doi.org/10.1016/j.apsusc.2016.07.044

Sastri, V. S., Bünzli, J. C., Rao, V. R., Rayudu, G. V. S., \& Perumareddi, J. R. (2003). Modern Aspects of Rare Earths and Their Complexes, 983, Elsevier, Amsterdam. https://doi.org/10.1016/B978-0-44451010-5.X5014-7

Satur, J. V., Calabia, B. P., Hoshino, M., Morita, S., Seo, Y., Kon, Y., Takagi, T., Watanabe, Y., Mutele, L., \& Foya, S. (2016). Flotation of rare earth minerals from silicate-hematite ore using tall oil fatty acid collector. Minerals Engineering, 89, 52-62. https://doi.org/10.1016/j.mineng.2016.01.004

Sorensen, E., \& Lundgaard, T. (1966). Selective Flotation of Steenstrupine and Monazite from Kvanefjeld Lujavrite, 17. Danish Atomic Energy Commission, Roskilde.

Sreenivas, T., \& Padmanabhan, N. P. H. (2002). Surface chemistry and flotation of cassiterite with alkyl hydroxamates. Colloids and Surfaces A: Physicochemical and Engineering Aspects, 205(12), 47-59. https://doi.org/10.1016/S09277757(01)01146-3

Taggart, A. F., \& Behre, H. A. (1945). Handbook of mineral dressing, ores and industrial minerals, 1905. John Wiley \& Sons, Hoboken.

Wang, C. H., Qiu, X. Y., Hu, Z., Li, H. W., Wang, T., \& Zou, J. J. (2012). Study on improved beneficiation technology for rare earth ores. 26th International Mineral Processing Congress, IMPC 2012: Innovative Processing for Sustainable Growth Conference Proceedings, 5782-5786.

Wills, B. A. (2006). Wills' Mineral Processing Technology, 456. Elsevier Science \& Technology Books, Oxford.

Yang, X., Satur, J. V., Sanematsu, K., Laukkanen, J., \& Saastamoinen, T. (2015). Beneficiation studies of a complex REE ore. Minerals Engineering, 71, 55-64. https://doi.org/10.1016/j.mineng.2014.10.005

Yang, Z., Wu, W., \& Bian, X. (2017). Synthesis of 3hydroxy-2-naphthyl hydroxamic acid collector: Flotation performance and adsorption mechanism on bastnaesite. Journal of the Southern African Institute of Mining and Metallurgy, 117(6), 593-598. https://doi.org/10.17159/24119717/2017/v117n6a10

Yu, J., Ge, Y., \& Hou, J. (2016). Behavior and mechanism of collophane and dolomite separation using alkyl hydroxamic acid as a flotation collector. Physicochemical Problems of Mineral Processing, 52(1), 155-169. https://doi.org/10.5277/ppmp160114

Zakharov, A. E., Ilie, P., Pol'kin, S. I., \& Solnyshkin, V. I. (1967). Reaction of Sodium Sulfide with Pyrochlore,
Zircon and Monazite in Flotation with Sodium Oleate. Içinde Flotation Properties of Rare Metal Minerals (ss. 71-82).

Zhang, J., \& Edwards, C. (2012). A review of rare earth mineral processing technology. 44th Annual Meeting of the Canadian Mineral Processors, 79-102.

Zhang, Jack, Zhao, B., \& Schreiner, B. (2016). Separation hydrometallurgy of rare earth elements, 259. Springer, Cham.

Zhang, W, Honaker, R. Q., \& Groppo, J. G. (2017). Flotation of monazite in the presence of calcite part I: Calcium ion effects on the adsorption of hydroxamic acid. Minerals Engineering, 100, 40-48. https://doi.org/10.1016/j.mineng.2016.09.020

Zhang, Wencai, \& Honaker, R. (2017). A fundamental study of octanohydroxamic acid adsorption on monazite surfaces. International Journal of Mineral Processing, 164, 26-36. https://doi.org/10.1016/j.minpro.2017.05.006

Zhang, Wencai, Honaker, R., \& Groppo, J. (2016). Fundamental study of the monazite-calcite flotation separation. IMPC 2016 - 28th International Mineral Processing Congress Proceedings.

Zhang, Wencai, \& Honaker, R. Q. (2018). Flotation of monazite in the presence of calcite part II: Enhanced separation performance using sodium silicate and EDTA. Minerals Engineering, 127, 318-328. https://doi.org/10.1016/j.mineng.2018.01.042

Zhang, X., Du, H., Wang, X., \& Miller, J. D. (2013). Surface chemistry considerations in the flotation of rare-earth and other semisoluble salt minerals. Minerals and Metallurgical Processing, 30(1), 2437. https://doi.org/10.1007/bf03402338

Zhang, Y., \& Anderson, C. (2017a). A comparison of sodium silicate and ammonium lignosulfonate effects on xenotime and selected gangue mineral microflotation. Minerals Engineering, 100, 1-8. https://doi.org/10.1016/j.mineng.2016.10.002

Zhang, Y., \& Anderson, C. (2017b). Surface Chemistry and Microflotation of Xenotime and Selected Gangue Minerals Using Octanohydroxamic Acid as the Collector. Journal of Sustainable Metallurgy, 3(1), 39-47. https://doi.org/10.1007/s40831-016-0081-5 
Review article/Derleme makale

DOI: 10.29132/ijpas.922811

EKLER

EK-1. Nadir toprak elementlerinin fiziksel, kimyasal ve termal özellikleri (Krishnamurthy \& Gupta, 2015)

\begin{tabular}{|c|c|c|c|c|c|c|c|c|}
\hline \multicolumn{9}{|c|}{ Fiziksel ve Kimyasal Özellikler } \\
\hline Element & Lantan & Seryum & Praseodim & Neodim & Samaryum & Evropiyum & Gadolinyum & Terbiyum \\
\hline Atom No & 57 & 58 & 59 & 60 & 62 & 63 & 64 & 65 \\
\hline$\underset{(\mathrm{g} / \mathrm{mol})}{\operatorname{Atom} \text { ağırlığı }}$ & 138.91 & 140.12 & 140.91 & 144.24 & 150.36 & 151.97 & 157.25 & 158.92 \\
\hline Yoğunluk (g/cm³) & 6.146 & 8.16 & 6.773 & 7.008 & 7.520 & 5.244 & 7.901 & 8.230 \\
\hline Atom $\underset{(\mathbf{p m})}{\text { yarıçapı }}$ & 187 & 182.5 & 182.4 & 181.4 & 180.4 & 185 & 180.4 & 177.3 \\
\hline $\begin{array}{c}\text { İyonik yarıçap } \\
(\mathbf{p m})\end{array}$ & 106.1 & 103.4 & 101.3 & 99.5 & 96.4 & 95 & 93.8 & 092.3 \\
\hline Renk (oksit) & Beyaz & Kirli beyaz & Siyah & Soluk mavi & Krem & Beyaz & Beyaz & Kahverengi \\
\hline Renk (çözelti) & Renksiz & $\begin{array}{c}\text { +3: renksiz } \\
+4: \text { turuncu-sar1 }\end{array}$ & Yeşil-sarı & Gül rengi & $\begin{array}{c}+2: \text { Koyu kirmızı } \\
+3: \text { Sarı }\end{array}$ & $\begin{array}{l}+2: \text { Soluk sarı } \\
+3: \text { Renksiz }\end{array}$ & Renksiz & Soluk pembe \\
\hline \multicolumn{9}{|c|}{ Termal Özellikler } \\
\hline $\begin{array}{l}\text { Ergime Noktası } \\
\quad\left(\text { metal }-{ }^{\circ} \mathrm{C}\right)\end{array}$ & 1918 & 798 & 931 & 1021 & 1074 & 822 & 1313 & 1356 \\
\hline $\begin{array}{l}\text { Ergime Noktası } \\
\quad\left(\text { oksit }-{ }^{\circ} \mathrm{C}\right)\end{array}$ & 2315 & $\begin{array}{l}\mathrm{Ce}_{2} \mathrm{O}_{3}: 2177 \\
\mathrm{CeO}_{2}: 2400\end{array}$ & 2183 & 2233 & 2335 & 2350 & 2420 & 2315 \\
\hline $\begin{array}{c}\text { Kaynama Noktası } \\
\left(\text { metal }-{ }^{\circ} \mathbf{C}\right)\end{array}$ & 3457 & 3426 & 3512 & 3068 & 1791 & 1597 & 3266 & 3223 \\
\hline $\begin{array}{c}\text { Kaynama Noktası } \\
\left(\text { oksit }-{ }^{\circ} \mathrm{C}\right)\end{array}$ & 4200 & $\begin{array}{l}\mathrm{Ce}_{2} \mathrm{O}_{3}: 3730 \\
\mathrm{CeO}_{2}: 3500\end{array}$ & 3760 & 3760 & 4118 & 4118 & Bilgi Yok & 4200 \\
\hline
\end{tabular}


Review article/Derleme makale

DOI: 10.29132/ijpas.922811

EK-1 (devamı). Nadir toprak elementlerinin fiziksel, kimyasal ve termal özellikleri (Krishnamurthy \& Gupta, 2015)

\begin{tabular}{|c|c|c|c|c|c|c|c|c|}
\hline \multicolumn{9}{|c|}{ Fiziksel ve Kimyasal Özellikler } \\
\hline Element & Disprosyum & Holmiyum & Erbiyum & Tulyum & İterbiyum & Lütesyum & İtriyum & Skandiyum \\
\hline Atom No & 66 & 67 & 68 & 69 & 70 & 71 & 39 & 21 \\
\hline$\underset{(\mathrm{g} / \mathrm{mol})}{\operatorname{Attom}}$ ağırlı̆̆ & 162.5 & 164.93 & 167.26 & 168.93 & 173.04 & 174.97 & 88.91 & 44.96 \\
\hline Yoğunluk (g/cm $\left.{ }^{3}\right)$ & 8.551 & 8.795 & 9.066 & 9.321 & 6.966 & 9.841 & 4.469 & 2.989 \\
\hline Atom yarıçapı (pm) & 178.1 & 176.2 & 176.1 & 175.9 & 193.3 & 193.3 & 180 & 162 \\
\hline İyonik yarıçap (pm) & 90.8 & 89.4 & 88.1 & 86.9 & 85.8 & 84.8 & 88 & 68 \\
\hline Renk (oksit) & Sarımsı beyaz & Sarımsı beyaz & Pembe & $\begin{array}{c}\text { Beyaz. } \\
\text { yeşilimtırak }\end{array}$ & Beyaz & Beyaz & Beyaz & Beyaz \\
\hline Renk (çözelti) & Soluk sarı-yeşil & Sarı & Pembe & Yeşilimtırak & $\begin{array}{c}\text { +2: Sarı } \\
+3: \text { Renksiz }\end{array}$ & Renksiz & Renksiz & Renksiz \\
\hline \multicolumn{9}{|c|}{ Termal Özellikler } \\
\hline $\begin{array}{l}\text { Ergime Noktası } \\
\left(\text { metal }-{ }^{\circ} \mathrm{C}\right)\end{array}$ & 1412 & 1474 & 1529 & 1545 & 819 & 1663 & 1522 & 1541 \\
\hline $\begin{array}{c}\text { Ergime Noktası } \\
\left(\text { oksit }-{ }^{\circ} \mathrm{C}\right)\end{array}$ & 2408 & 2415 & 2344 & 2341 & 2355 & 2490 & 2425 & 2485 \\
\hline $\begin{array}{c}\text { Kaynama Noktası } \\
\left(\text { metal }-{ }^{\circ} \mathbf{C}\right)\end{array}$ & 2562 & 2695 & 2863 & 1947 & 1194 & 3395 & 3338 & 2831 \\
\hline $\begin{array}{l}\text { Kaynama Noktası } \\
\left(\text { oksit }-{ }^{\circ} \mathrm{C}\right)\end{array}$ & 3900 & 3900 & 3290 & 3945 & 4070 & 3980 & 4300 & Bilgi Yok \\
\hline
\end{tabular}

